San Jose State University

SJSU ScholarWorks

Master's Theses

Master's Theses and Graduate Research

1999

\title{
Uncertainty evaluation of the 1994 UBC base shear formula for concrete moment-resisting frames
}

Ali Mehrabian

San Jose State University

Follow this and additional works at: https://scholarworks.sjsu.edu/etd_theses

\section{Recommended Citation}

Mehrabian, Ali, "Uncertainty evaluation of the 1994 UBC base shear formula for concrete momentresisting frames" (1999). Master's Theses. 1322.

DOI: https://doi.org/10.31979/etd.ergx-n2n5

https://scholarworks.sjsu.edu/etd_theses/1322

This Thesis is brought to you for free and open access by the Master's Theses and Graduate Research at SJSU ScholarWorks. It has been accepted for inclusion in Master's Theses by an authorized administrator of SJSU ScholarWorks. For more information, please contact scholarworks@sjsu.edu. 


\section{INFORMATION TO USERS}

This manuscript has been reproduced from the microfilm master. UMI films the text directly from the original or copy submitted. Thus, some thesis and dissertation copies are in typewriter face, while others may be from any type of computer printer.

The quality of this reproduction is dependent upon the quality of the copy submitted. Broken or indistinct print, colored or poor quality illustrations and photographs, print bleedthrough, substandard margins, and improper alignment can adversely affect reproduction.

In the unlikely event that the author did not send UMI a complete manuscript and there are missing pages, these will be noted. Also, if unauthorized copyright material had to be removed, a note will indicate the deletion.

Oversize materials (e.g., maps, drawings, charts) are reproduced by sectioning the original, beginning at the upper left-hand comer and continuing from left to right in equal sections with small overlaps. Each original is also photographed in one exposure and is included in reduced form at the back of the book.

Photographs included in the original manuscript have been reproduced xerographically in this copy. Higher quality 6" $\times 9$ " black and white photographic prints are available for any photographs or illustrations appearing in this copy for an additional charge. Contact UMI directly to order.

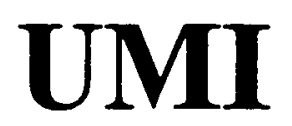

A Bell \& Howell Information Company 300 North Zeeb Road, Ann Arbor MI 48106-1346 USA 

UNCERTAINTY EVALUATION OF THE 1994 UBC BASE

SHEAR FORMULA FOR CONCRETE MOMENT-RESISTING FRAMES

\begin{abstract}
A Thesis
Presented to

The Faculty of the Department of Civil Engineering and Applied Mechanics San Jose State University
\end{abstract}

In Partial Fulfillment

of the Requirements for the Degree

Master of Science

by

Ali Mehrabian

August 1996 
UMI Number: 1381433

\section{Copyright 1996 by \\ Mehrabian, Ali}

All rights reserved.

UMI Microform 1381433

Copyright 1996, by UMI Company. All rights reserved.

This microform edition is protected against unauthorized copying under Title 17, United States Code.

\section{UMI \\ 300 North Zeeb Road \\ Ann Arbor, MI 48103}


(C) 1996

\section{Ali Mehrabian}

ALL RIGHTS RESERVED 
APPROVED FOR THE DEPARTMENT OF CIVIL ENGINEERING

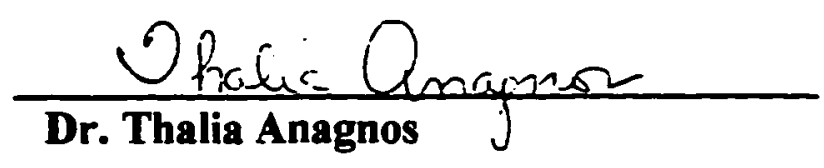

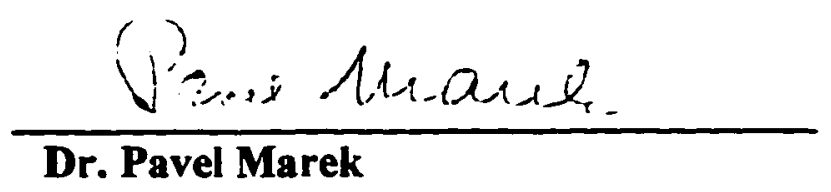

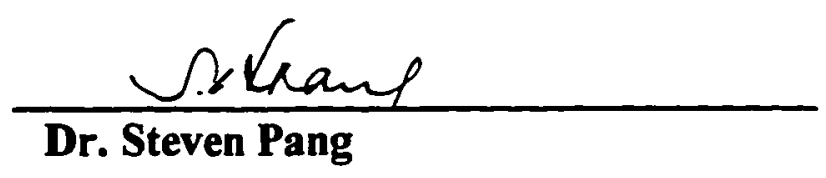

APPROVED FOR THE UNIVERSITY

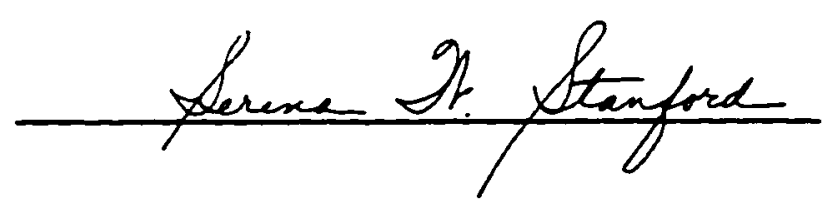




\begin{abstract}
UNCERTAINTY EVALUATION OF THE 1994 UBC BASE SHEAR FORMULA FOR CONCRETE MOMENT-RESISTING FRAMES
\end{abstract}

\author{
By Ali Mehrabian
}

This study investigates the Uniform Building Code 1994 (UBC-94) equivalent static analysis approach in calculating the base shear forces of 14 reinforced concrete momentresisting frame structures (RCMRFS). The UBC-94 base shear Formula [28-1] was investigated using an uncertainty evaluation technique, utilizing the $M$-Star ${ }^{\mathrm{IM}}$ computer program. The uncertainty was assigned to main parameters of this formula, specifically $T$ and $R_{w}$, by means of appropriate frequency distributions, and a system ductility factor was substituted for $R_{w}$ to account for the ductility characteristics of the structures.

This study reveals that the current values of $R_{w}$ are unconservative for RCMRFS with low system ductilities. This study also suggests that there is potential for the UBC-94 formula for fundamental period estimation of RCMRFS to become a more conservative formula. The results indicate that for medium-rise (130-300 ft.) RCMRFS with high system ductility factors, the effects of uncertainty in $\mathrm{T}$ and $R_{w}$ are minimized. In this case the UBC-94 formula provides conservative design forces. 


\section{ACKNOWLEDGMENTS}

The author would like to take this opportunity to thank those individuals who, without their efforts and support, this work would not have been possible.

I would like to thank Dr. Thalia Anagnos for her constant efforts, her confidence in me, and above all, her patience in seeing this project through. I also would like to thank Dr. Pavel Marek for his unlimited support, his endless source of knowledge, and his dedication in guiding me throughout this thesis. A great deal of thanks also goes to Dr. Steven Pang for his valuable time, his encouragement, and his positive feedback.

Furthermore, I would like to thank my parents and my sisters for their dedication and constant support throughout the time spent on this work and the many years leading up to this time. Moreover, I would like to thank (in alphabetical order) Deborah Casey, Hamid Emamifar, David Kobayashi, Hossein Nik-Ahd, and Tasnim Sharif for their endless support and friendship throughout my time at San Jose State University, and on to the present.

Finally, the author greatly appreciates the help of (in alphabetical order) Dr. M. Fouad Bendimerad from Risk Management Solutions, Dr. Robert Englekirk from Robert Englekirk Consulting Structural Engineers, Dr. Bahman Lashkari-Irvani from EQE International, and Dr. Haresh Shah from Stanford University for allowing me to use the results of their work. The author gratefully acknowledges the help of Mr. Roy Fewell from International Conference of Building Officials. 


\section{TABLE OF CONTENTS}

Chapter 1: Introduction

1.1. Motivation of Study 1

1.2. Objectives 3

1.3. Scope 5

Chapter 2: Equivalent Static Approach and Code Formulas

2.1. Background 7

2.2. Basis of UBC Equivalent Static Force Procedure 8

2.3. Code Formulas for Base Shear 10

Chapter 3: Period Estimation of Reinforced Concrete Moment-Resisting

Frame Structures

3.1. Introduction 14

$\begin{array}{ll}\text { 3.2. Current Practice } & 14\end{array}$

3.2.1. Method A: Approximate Formulas 15

3.2.2. Method B: Raleigh's Formula 16

$\begin{array}{ll}\text { 3.3. Background and Previous Studies } & 17\end{array}$

3.4. Fundamental Period, Seismic Response, and other

Building Characteristics 
3.5. Shortcomings of the Code Period Estimation Formula 23

3.6. Potential Refinement of Database 25

3.6.1. Refining Criteria 26

$\begin{array}{ll}\text { 3.6.2. Excluded Buildings } & 28\end{array}$

3.7. Distribution of Building Periods 29

3.7.1. Regression Analysis: Purpose, Assumptions, and Methodology 30

3.7.2. Results of Regression Analysis and Comparison with UBC 32

3.8. Summary 34

Chapter 4: Structural System Factor, $R_{w}$, and Ductility Demand

4.1. Introduction 41

4.2. Structural System Factor, $R_{w}$, and Current Code Approach 42

4.3. Elastic Design and Susceptibility to Damage 45

4.4. Ductility Factor and System Ductility 46

4.5. Development of System Ductility as a Function of $R_{w} \quad 50$

4.5.1. Previous Attempts $\quad 51$

4.5.2. Appropriate Relationship 52

4.6. Structural System Factor, $R_{w}$, Distributions 56

4.7. Summary 61 
Chapter 5: Evaluation of Uncertainty in the Base Shear Formula

$\begin{array}{ll}\text { 5.1. Background and Objectives } & 70\end{array}$

5.2. Method of Analysis of Two or More Variables 71

5.3. Parametric Assumptions 72

5.4. Developing the Histograms 75

5.4.1. Histogram of Building Period, $T$

5.4.2. Histogram of Structural System Factor, $R_{w} \quad 76$

5.5. Uncertainty Evaluation Using M-Star 77

5.6. Analysis and Discussion of Results and Comparison with UBC 78

Chapter 6: Summary and Conclusions

6.1. Summary of Study 95

$\begin{array}{ll}\text { 6.2. Conclusions } & 96\end{array}$

6.3. Recommendations 99

$\begin{array}{ll}\text { References } & 102\end{array}$

$\begin{array}{ll}\text { Apperdix A } & 106\end{array}$ 


\section{LIST OF TABLES}

\section{Chapter 3}

3-1 Data Set of Reinforced Concrete Frame Structures

Used by Gates and Foth

3-2 Refined Database of RCMRF Structures: Characteristics and

Corresponding Recorded Earthquakes of Bendimerad et al. Study

3-3 Regression Analysis Results for Average Measured Periods

in both Directions of the Refined Database

Chapter 4

4-1 Structural Systems and Structural System Factors, $R_{\mathrm{w}}$

4-2 Results of Calculated Structural System Factor, $R_{w}$, for RCMRF

Structures with System Ductility Factors of 1, 2, 3, and 4

Chapter 5

5-1 Results of Uncertainty Evaluation of UBC-94 Base Shear

Formula 28-1 for Buildings with System Ductility $=1$

5-2 Results of Uncertainty Evaluation of UBC-94 Base Shear

Formula 28-1 for Buildings with System Ductility $=2$

5-3 Results of Uncertainty Evaluation of UBC-94 Base Shear 
Formula 28-1 for Buildings with System Ductility $=3$

5-4 Results of Uncertainty Evaluation of UBC-94 Base Shear

Formula 28-1 for Buildings with System Ductility $=4$ 


\section{LIST OF FIGURES}

\section{Chapter 3}

3-1 Comparison of the UBC-94 Period Estimation Formula

with Linear Regression Line for $\mathrm{T}$ from Instrumental Records

3-2 Comparison of 70\% Confidence Interval Limits

with the UBC-94 Period Estimation Formula

Chapter 4

4-1a Ductility of an Elastic-Perfectly Plastic System 66

4-1b Hysteretic Energy of an Inelastic System 66

4-1c Cyclic Ductility Factor 66

4-2 Design Spectrum for Maximum Probable Earthquake (MPE)

$\begin{array}{ll}\text { with 5\% Damping } & 67\end{array}$

4-3 Extracted Values of Design Elastic Spectral Acceleration, $S_{\mathrm{ae}}$,

for MPE from Figure 4-2 68

4-4 Structural System Factor, $R_{w}$, vs. Period, T, for RCMRF

Structures with System Ductility Factors $\mu=1,2,3$, and 4

69

Chapter 5

5-1 A Truncated Normal Distribution for Average Period, T, 
for Building 8 of Table 3-3

5-2 A Sample Uniform Distribution for $\mathrm{R}_{\mathrm{var}} \quad 88$

5-3 A Sample of the Resulting M-Star Frequency Distribution for Base Shear Coefficient, V/ W, for Building 8 with

System Ductility Factor $=1$

5-4 Comparison of the Lower Bounds of the BSC

Distributions with UBC-94 Formula

5-5 Comparison of the Median Values of the BSC

Distributions with UBC-94 Formula

5-6 Comparison of the 99 Percentile Values of the BSC

Distributions with UBC-94 Formula

5-7 Comparison of the 99.5 Percentile Values of the BSC

Distributions with UBC-94 Formula

5-8 Comparison of the Upper Bounds of the BSC

Distributions with UBC-94 Formula 


\section{Chapter 1}

\section{INTRODUCTION}

\subsection{Motivation of Study:}

Earthquakes are among the most complicated phenomena of nature. Many aspects of earthquakes are not yet fully understood and explained. In the history of civilization, many cities have been damaged by earthquakes, and earthquakes are still causing structural failures and catastrophic casualties. Even with the dramatic improvement in seismic specifications, many buildings are being designed without adequate consideration of seismic forces. Earthquake design regulations permit the use of the minimum code requirements in design. However, minimum code requirements do not always satisfy the desired criteria for all design circumstances simply because of the shortcomings of the rationale behind many code formulas. Much more research is needed to fully justify the implementation of code formulas in design and to understand the limitations of these formulas.

The ultimate goal of the structural designer is to implement a safe, economical, and efficient design. The design is based on a prediction of the actual behavior of the structure under prescribed loading. To describe the behavior of the actual structure, it is necessary to construct a mathematical model of the structure that can closely capture the actual 
response of the structure subjected to a dynamic load such as earthquake excitation. Due to the complex response of the structure during an earthquake, it is difficult to accurately predict and formulate this response. Presently, the common procedure for the seismic design of a structure is to perform an equivalent static lateral-force analysis of the lateral load resisting system and select dimensions so that members can resist these loads within the allowable code strength and serviceability criteria. The latest edition of Uniform Building Code (UBC-94) indicates that the equivalent static lateral-force procedures shall be performed on buildings meeting the requirements of Section 1627.8 while dynamic analysis shall be used for all other buildings not meeting these requirements (see UBC-94, Chapter 16, Section 1627.8).

The current equivalent static analysis approach used in UBC-94 can yield a realistic design if the initial base shear force estimation formula can closely capture the actual base shear force that the building will experience during a given earthquake. In this case, the number of design iterations can be reduced. The accuracy of this formula could be substantially improved if the data from instrumental records of the buildings, collected during actual earthquakes, were to be used for examining this empirical formula. In addition, due to the complexities and uncertainties in earthquake design and in predicting the ground shaking in future earthquakes, a more pragmatic formula must consider some level of tolerable uncertainties in different parameters of the formula. The presence of these uncertainties 
would be a good indication that a probabilistic approach with an appropriate probability distribution for each parameter is indeed suitable for this kind of problem.

While a probabilistic approach seems to be appropriate, many probabilistic distributions are difficult to combine analytically, and thus, closed-form solutions can't be obtained easily. Using computer programs such as M-Star can make the problem much easier to solve. $M$-Star is a simulation-based computer program used for the evaluation of formulas with one or more variables in which each variable is represented by its probabilistic distribution. The M-Star computer program will be discussed in detail in Chapter 5 .

\subsection{Objectives:}

In an attempt to offer an improvement in the current, empirical seismic base shear formula of Uniform Building Code [UBC-94], this study proposes an alternate point of view. The main objectives of this study are:

1. To examine, using the data from instrumental records of several buildings, the base shear force Formula [28-1] of UBC-94 for reinforced concrete momentresisting frame (RCMRF) structures. This formula was introduced in the SEAOC Blue Book 1988 and adopted by International Conference of Building 
Officials (ICBO) in 1988. Buildings designed according to this formula should have performed adequately during the recorded strong motions.

2. To study the influence of structural characteristics, structural properties, and ground motion characteristics on the period and response of RCMRF structures during strong earthquake motions.

3. To study the logic behind the presence of different parameters, such as period and the structural system factor, in the design base shear force Formula [28-1]. These parameters will be studied in detail in the next sections of this study.

4. To introduce a probabilistic approach, using Monte Carlo Simulation, in order to understand the influence of uncertainty in different parameters on the base shear force Formula [28-1] of UBC-94.

5. To recommend possible refinement and improvements in the base shear force computation for code design purposes. An approach incorporating suggested refinements that may lead to improvements in the code seismic design formula is proposed in subsequent chapters of this study. 


\subsection{Scope:}

In this study, the base shear formula of the UBC-94 and its parameters will be evaluated in detail. For each parameter, the current practice, the previous work(s), the rationale behind each work, and the shortcomings of the present code formulation will be presented and discussed. Finally, an uncertainty evaluation of the base shear formula will be presented and the results will be analyzed and discussed. The entire study is presented in 6 chapters as follows:

Chapter 1 outlines the motivation, the objectives, and the scope of the study. In Chapter 2 , the equivalent static approach of the UBC and two methods of calculating the period of different structures are presented. The influence of the structural characteristics and their effects on the transient nature of the structural response and on the fundamental period of structures during strong ground motions is discussed in Chapter 3. The database of previous research used in the period estimation formulation of UBC-94 is presented, and a refining criteria is also established in this chapter. At the end of Chapter 3, the database is refined based on the established criteria, and a methodology for developing the probabilistic distributions for the period of the structures is presented.

Devoted entirely to the structural system factor, $R_{w}$, Chapter 4 includes different definitions of system ductility factor. In this chapter $R_{w}$ is analyzed, and finally, based on 
previous works, a formula is developed to relate the system ductility of a structure to other structural characteristics. Chapter 4 also includes a methodology for developing the probabilistic distributions for the structural system factor based on the assumed system ductility and the period of the structure.

An uncertainty evaluation of the base shear formula is presented in Chapter 5 . In this chapter the probabilistic approach is discussed and the $M$-Star program is introduced. All other information in previous chapters are combined in this chapter. It is in Chapter 5 that the base shear formula is analyzed by developing appropriate distributions for its parameters. The distributions of the base shear coefficients resulting from uncertainty evaluation are compared in this chapter with the base shear coefficients from UBC base shear formula. In the final stages of this chapter, the uncertainty evaluation results are presented in different tables and figures, and the results are discussed. Chapter 6 includes a summary and conclusions of this study and it offers several recommendations for future studies. 


\section{Chapter 2}

\section{EQUIVALENT STATIC APPROACH AND CODE FORMULAS}

\subsection{Backeround:}

The mass, elastic properties (flexibility or stiffness), and energy-loss mechanism (or damping) are the primary physical properties of any linearly elastic structural or mechanical system subjected to an external source of excitation or dynamic loading [10]. When performing linear-elastic, dynamic analysis, using a time-history analysis or a response spectral analysis, the model of the structure is characterized by its mass, stiffness, and damping [47]. While dynamic analyses are appropriate for analyzing the dynamic behavior of simple structures under earthquake loading, they are not usually used for preliminary member sizing or for simple structures since they are complicated and can take a lot of time to perform.

Currently, UBC-94 design criteria permit the use of an equivalent static lateral force procedure for regular structures to specify the minimum base shear load caused by earthquake excitation. Regular structures are defined in Section 1627.5.2 of UBC-94 as, "structures with no physical discontinuities in plan or vertical configuration or in their lateral-force-resisting system such as the irregular features described in Section 1627.5.3" [26]. The minimum base shear force, calculated from this procedure, is distributed to all 
members of the load resisting system according to their relative stiffnesses. In code design formulas for computing the base shear of a regular structure, the dynamic characteristics of the structure are represented by the seismic dead load of the structure and by the fundamental period. According to Section 1628.1 of UBC-94, the seismic dead load of a structure is the total dead load of the structure and applicable portions of other loads of the structure such as 25 percent of the live load for warehouse occupancy structures [26]. As will be discussed in the following sections of this study, other factors such as soil characteristics and the probability of occurrence of earthquakes in different geographic regions (zone factors) are also considered in the base shear formula of UBC-94 in the form of additional parameters such as $\mathrm{S}$ and $\mathrm{Z}$.

\subsection{Basis of UBC Equivalent Static Force Procedure:}

To fully explain the limitations and the shortcomings of the equivalent static force procedure of UBC-94, it is useful to briefly outline the basis of this procedure. The basis of the different parameters of the UBC base shear formula and the descriptions of their shortcomings can be found throughout Chapters 3, 4 and 5 .

The intent of the equivalent static force procedure is to represent the dynamic characteristics of the structure by the fundamental period of the structure, $T$, the structural system factor, $R_{w}$, and the seismic dead load of the structure, W (see Section 2.1 for 
definition of seismic dead load). Other site dependent factors such as ground motion magnification characteristics of different types of soil and the probability of occurrence of earthquakes in different geographic regions (zone factors) are also considered in the base shear formula in the form of additional parameters $S$ (site coefficient for soil characteristics) and $Z$ (seismic zone factor) respectively.

The minimum base shear force calculated from this procedure is distributed to different stories of the structure according to their relative stiffnesses, with the intent of replacing time varying inertia forces by equivalent static forces applied at story levels ([26] and [43]). The relative magnitudes of these equivalent story forces are based on simplifying assumptions for mode shapes and modal participation. It is further assumed that the story drift ratios and masses are reasonably uniform over the height of the building. A complete list of the assumptions and provisions for the static lateral force procedures can be found in References [26] and [43]. Overall, these provisions are intended to provide life safety and not property protection during major earthquakes [43].

The force level calculated from the UBC base shear formula is based on the assumption that during major earthquake ground motion, the structure will experience several cycles of inelastic deformation [43]. This level depends on the type of structural system, and its capability to dissipate energy and sustain these deformations without collapse. The resulting seismic forces are based on allowable stress design [43]. 


\subsection{Code Formulas for Base Shear:}

The UBC-94 [26] prescribed an equivalent static base shear force $V$, in any direction, to be computed from the formula:

$$
V=\frac{Z I C}{R_{w}} W
$$

where $\quad C=\frac{1.25 S}{T^{23}} \leq 2.75$

Substituting Formula [2-2] in [2-1] yields,

$$
V=\frac{Z(1.25 S) I}{\left(T^{2 / 3}\right) R_{w}} W
$$

where each parameter is defined as:

$T=$ fundamental period of vibration of the structure in the direction under consideration (in seconds).

$V=$ the total design lateral force or shear at the base.

$Z=$ seismic zone factor given in Table 16-I of UBC-94.

$I=$ seismic importance factor given in Table 16-K of UBC-94. 
$S=$ site coefficient for soil characteristics given in Table 16-J of UBC-94.

$R_{w}=$ structural system factor given in Tables 16-N and 16-P of UBC-94.

$W=$ the total seismic dead load defined in Section 1628.1 of UBC-94.

Formula [2-1] was introduced in the 1988 edition of UBC for the first time. Prior to the 1988 edition, the UBC used a similar formula to calculate base shear force in the form:

$$
V=Z I K C S W
$$

where $C$ was calculated from:

$$
C=\frac{1}{15 \sqrt{T}} \leq 0.12
$$

In Formulas [2-4] and [2-5], I is an importance factor equal to 1.5 for essential buildings and 1.0 for other buildings, $\mathrm{T}$ is the period of the structure, $\mathrm{S}$ is a coefficient for sitestructure resonance not to be less than one, $\mathrm{K}$ is a horizontal force factor ranging from 0.67 to $1.33, \mathrm{Z}$ is a seismic zoning factor equal to $0.25,0.5$, and 1 for seismic zones 1,2 , and 3 respectively, and $\mathrm{W}$ is the total dead load plus 25 percent of the floor live load for storage and warehouse occupancies. Formula [2-1] and Formula [2-4] are both empirical 
formulas, and they are analogous. The values of $\mathrm{K}$ in Formula [2-4] have been reduced by a factor of $1 / 8$ and substituted by $1 / R_{w}$.

Formula [2-3] can be used only for regular structures (see Section 1627.5.2 of UBC-94 for the definition of regular structures), and a dynamic analysis is required in other cases. At the beginning stage of the design, the properties of members are not known, making it difficult to perform a dynamic analysis. Thus, Formula [2-3] of UBC-94 is used to calculate the preliminary base shear force for the initial evaluation of member forces and sizing of members. The UBC-94, Section 1627.8 .3 requires a dynamic analysis to be performed for the following building types:

1. Structures 240 feet or more in height.

2. Structures having geometric vertical irregularities, stiffness irregularities in different directions, and irregularities in the distribution of the mass. The criteria for these irregularities are defined in Uniform Building Code.

3. In areas of high seismicity (seismic zones 3 and 4), structures over five stories or 65 feet in height which do not have the same structural system throughout their height. 
4. Regular or irregular structures, located on soil profile type S4, with a period greater than 0.7 seconds.

In order to perform a dynamic analysis of a structural frame, the properties of the members of the frame must be defined. Using the dynamic analysis, the designer can verify the adequacy of the member sizes based on the desired design criteria. To reduce the number of design iterations, it is important for the designer to have a reliable base shear formula at the preliminary stage of the design to provide a close approximation of the forces induced in the frame by the earthquake excitation. 


\section{Chapter 3}

\section{PERIOD ESTIMATION OF REINFORCED CONCRETE MOMENT- RESISTING FRAME STRUCTURES}

\subsection{Introduction:}

In this chapter the current practices for estimation of the fundamental period of reinforced concrete moment-resisting frame structures are discussed, and previous studies on which the current code formulas are based are reviewed. A database of the previous studies and the methodology adopted in each study are presented along with a discussion of methodology shortcomings. Next, the author discusses his attempt to establish a consistent criteria to refine the database and adopt a more accurate formula for estimating the period of the reinforced concrete moment-resisting frames. Finally, a procedure is presented for developing normal distributions to account for the variation in the estimated periods.

\subsection{Current Practice:}

Formula [2-3] indicates the importance of a reliable estimation of the fundamental period in the calculation of the base shear design force. The UBC-94 permits the use of a 
deterministic value for period, $T$, to be used to obtain the base shear, $V$. Two methods of estimating $\mathrm{T}$ are recommended:

1. Method A: Approximate Empirical Formulas

2. Method B: Raleigh's Formula

The two methods are presented in the following sections.

\subsubsection{Method A: Approximate Formulas:}

Section 1628.2.2 of UBC-94 recommends that for all buildings, the value of $\mathrm{T}$ may be approximated from the following formula:

$$
T=C_{z}\left(h_{n}\right)^{3 / 4}
$$

where:

$$
\begin{aligned}
& C_{t}=0.035 \text { for steel moment-resisting frames } \\
& C_{t}=0.030 \text { for reinforced concrete moment-resisting frames and } \\
& \text { eccentrically steel braced frames } \\
& C_{t}=0.020 \text { for all other buildings }
\end{aligned}
$$

and,

$$
\begin{aligned}
h_{n}= & \text { height, in feet, above the base to the level } n \text { (the level which is } \\
& \text { uppermost in the main portion of the structure). }
\end{aligned}
$$


Formula [3-1] was first introduced in the 1988 SEAOC "Blue Book" and was adopted by the International Conference of Building Officials (ICBO) in the 1988 Uniform Building Code [26]. Prior to the 1988 Edition, the UBC period formula was given by:

$$
T=0.1 N
$$

where $N$ is the total number of stories above the base. Therefore, Formula [3-1] represents an important change in the UBC for period computation in design.

\subsubsection{Method B: Raleigh's Formula:}

Using this method, the fundamental period, $T$, of the building may be estimated using the structural properties and deformational characteristics of the resisting elements [26]. This requirement may be satisfied by using the following formula:

$$
T=2 \pi\left[\sum_{i=l}^{n}\left(w_{i} \delta_{i}^{2}\right)+\left(\mathrm{g} \sum_{i=l}^{n} f_{i} \delta_{i}\right)\right]^{1 / 2}
$$

where:

$$
\begin{aligned}
& f_{i}=\text { seismic lateral force at level } \mathrm{i} \\
& w_{i}=\text { weight of the reactive mass (or portion of } \mathrm{W} \text { ) which is located } \\
& \text { at or is assigned to level } \mathrm{i}
\end{aligned}
$$




$$
\begin{aligned}
& \delta_{1}=\text { static lateral displacement at level i due to force } f_{1} \\
& g=\text { acceleration of gravity }
\end{aligned}
$$

In the preliminary design stage, none of the above parameters, except $g$, is known and Formula [3-3] can't be used. Therefore, the designer must rely on approximate formulas such as Formula [3-1].

According to UBC-94 [26], the value of T from Method B (Raleigh's Formula) shall not be more than 30 percent greater than the value of $T$ obtained from Method $A$ (Approximate Formula) in seismic zone 4 and not more than 40 percent greater in seismic zones 1,2 , and 3 .

\subsection{Background and Previous Studies:}

According to Reference [8], Formula [3-1] is based on an earlier recommendation by the Applied Technology Council (ATC) in 1982 (publication ATC 3-06 [3]), which prescribed a $C_{t}$ value of 0.025 for reinforced concrete frames. This ATC recommendation was originally based on the 1975 Gates and Foth study [18]. Gates and Foth examined data from 14 high-rise (more than 6 stories) buildings in which strong motion was recorded during the 1971 San Fernando earthquake. The period values were estimated from accelerograms recorded along the transverse and longitudinal directions of the buildings. 
The list of these buildings is reported in Table 3-1. The objective of the Gates and Foth study was to compare the data from these buildings to approximate formulas for period estimation computation such as $T=0.1 N$ and $T=0.035\left(h_{n}\right)^{3 / 4}$. The Gates and Foth study recommended that the formula $T=0.025\left(h_{n}\right)^{3 / 4}$ be considered as a lower limit of the period value for reinforced concrete space frame structures. Establishing a formula for estimating the minimum values for structural period leads to a conservative approach for calculating the base shear forces because, as shown in Formula [2-3], lower periods result in higher base shears for RCMRF structures. However, the Gates and Foth recommended value of $C_{t}=0.025$ was questioned by the concrete industry on the grounds that most of the 14 buildings in the database have substantial infills and rigidities that would bring the buildings close to a shear wall-frame category [21].

Five of the 14 buildings in the Gates and Foth database were investigated in a series of studies on the San Fernando 1971 earthquake sponsored by the National Oceanic and Atmospheric Administration (NOAA) in 1973 [35]. The objective of these investigations was to interpret the buildings' response through dynamic analyses of their structural systems using the recorded motion at the ground level (or basement) as input. Included in the NOAA report was a study by Mulhem and Maley [35] reporting pre-earthquake, during earthquake, and post-earthquake periods of 70 instrumented buildings in the Los Angeles area. All 14 buildings used by Gates and Foth are included in the Mulhem and Maley study. 
The main shortcoming of the Gates and Foth study is that there are no data available regarding the physical characteristics of the 14 buildings selected as frame structures. No floor or elevation plans were included and no description was given about the buildings and the nature of their lateral load-resisting systems. Floor plans of buildings $1,3,5$, and 14 of References [18] and [8] show various shear walls at the lower levels of these buildings. There are also inconsistencies between building classifications in the Mulhern and Maley Study and the Gates and Foth Study. For example, building 13 classified by Gates and Foth as a frame structure appears as a shear wall structure in the Mulhern and Maley classification.

In 1988, Bertero, Bendimerad, and Shah [8] published a comprehensive report in which they investigated and examined the approximate formula adopted by UBC for computing the period of reinforced concrete moment-resisting frame structures. The new data set used in this report showed that the formula $T=0.035\left(h_{n}\right)^{3 / 4}$ represents a lower limit of the period of a reinforced concrete frame structure at the time when its response is controlled by the frame alone [8]. This means that to be consistent with the UBC-88 assumptions, it was assumed in the Bertero et al. report that the non-structural components of a RCMRF structure have no significant effect on its period (see Section 3.5, Item 2). 
The data set was later expanded and refined in an extension study by Bendimerad, Shah, and Hoskins in 1991 [7]. While the new data set presented in the extension study included seven additional buildings with RCMRF lateral load resisting systems in both principal directions, it excluded several buildings from the database of the previous study. According to the extension study, the excluded buildings could not qualify as momentframe (MRF) buildings or had insufficient available information to establish them as MRFs. Table 3-2 shows the buildings in the extension study and the related earthquake records for these buildings. In Table 3-2, buildings labeled 1 to 10 are special (ductile) moment-resisting frames and buildings labeled 11 to 18 are non-ductile, moment-resisting frames. From the analysis of these 18 buildings, Bendimerad et al. recommended that a value of $C_{t}=0.035$ to be adopted in design procedures as a conservative lower bound for concrete moment-resisting frame structures in Formula [3-1]. They also concluded the following [7]:

1. There is no apparent evidence that the period values for the ductile moment frame buildings are lower than the period values for the non-ductile frame buildings. It is not an established fact that the drift control and other detailing requirements necessarily increase the stiffness and lower the period values of reinforced concrete moment-resisting frame buildings. 
2. The dynamic behavior of mixed structural systems (for example, shear wall in one direction and moment-resisting frame in the other direction) can be changed significantly in comparison with the RCMRF structural systems in both directions [7]. For this reason, when evaluating observed periods of pure moment-resisting frame buildings, mixed lateral load-resisting systems should not be included with the data.

3. By taking into consideration the relative rigidity between the principal directions of the building, the present UBC approximate period formula based on the height of the building could be substantially improved.

\subsection{Fundamental Period, Seismic Response, and other Building Characteristics:}

In an attempt to examine and possibly offer an improvement to the existing UBC-94 empirical relationships for estimating the period values of reinforced concrete momentresisting frames, it is essential to understand the time varying nature of the building response in order to establish rational correlations between period values, seismic response, and building characteristics.

Seismic records obtained in the buildings indicate that, during an earthquake excitation, the building response is highly non-stationary [7]. This means that both the excitation and 
the response are essentially transient in nature, and the building exhibits different dynamic characteristics with the changes in the amplitude of the motion. The non-stationary behavior of the buildings makes it difficult to assign a single fundamental period value for a building from the actual instrumental records. The period of motion of a structure affects the type of response it experiences during an earthquake excitation. Additionally, "a record along one direction of the building incorporates some cross-correlation representing the response of the building in other direction" [7]. This effect is minimized if the plan of the building is fairly regular (see Section 1627.5, UBC-94 for definition of regular buildings) along its principal directions.

Another important complication that could significantly affect the fundamental period value of a structure is stiffness degradation. This degradation in the stiffness is of particular importance in reinforced concrete structures because of the sensitivity of concrete to degradation. During strong earthquake motion, if the building sustains any damage, there would be a reduction in the stiffiness due to the cracking of members, local spalling of the concrete, and slipping and reduction in the effective modulus of the reinforcing steel [22]. Numerous studies by Bertero [9], Mulhern and Maley [35], Del Valle and Prince [11], Pardeon [40], Gulkan and Sozen [22], and other researchers revealed that there is always some permanent stiffness loss in reinforced concrete structures that have undergone strong ground motion. These studies have shown that the 
post-earthquake period of a reinforced concrete structure is generally longer than the preearthquake period for structures subjected to strong earthquakes.

In summary, the studies mentioned above demonstrate that the amount of stiffness degradation experienced during the earthquake should be considered in the interpretation of building periods. Consequently, to determine building periods from instrumental records, it is necessary to consider the degree of damage to the building during the earthquake. Typically, the period increases during the strong shaking phase, then decreases, but does not return to the pre-earthquake value, as the building comes back to rest.

\subsection{Shortcomings of the Code Period Estimation Formula:}

As explored in the previous sections of this study, current building code formulas for approximating the period values of structures are simplifications of the real problem. The main shortcomings of the present approximate formulas for estimating building periods are:

1. Lack of recognition of the stiffness and ductility characteristics of the building. For example, as shown in Reference [7], two buildings with the same type of concrete lateral load resisting frame system (such as concrete moment-resisting 
frames) and the same height could exhibit different period values during strong ground motion due to their different stiffness characteristics, among other factors. The current UBC formula assigns the same $T$ value for both of these buildings.

2. The participation of non-structural components is not included in the analysis. As shown in Reference [8], during strong earthquakes non-structural components of the lateral load resisting system may participate and change the period of the building significantly. The current UBC period formula simplifies the problem and assumes no participation of non-structural components. Further studies are needed to determine the degree of participation of non-structural components during the strong ground motion.

3. The effects of foundation type and soil-structure interaction on building period is unclear in the current code approach. The database on which the current code period-estimation formula is based (such as Reference [8]) includes many structures with different types of foundations. For example, the following buildings of Table 3-1 have different types of foundations: buildings 1 and 14 are supported by 38 -inch deep pile caps supported by poured-in-place reinforced concrete friction piles, buildings 5 and 10 are supported by reinforced concrete 
footings, and there is no information available on the type of foundation for buildings 4,7 , and 18 .

\subsection{Potential Refinement of Database:}

Due to the non-stationary effects described in Section 3.4, the interpretations of the building motion during an earthquake from actual instrumental records are complicated. These interpretations are further complicated by the shortage of available instrumental records from reinforced concrete moment-resisting frame structures.

To investigate the adequacy of the approximate formula for RCMRF structures, it is critical to establish a database containing only structures with reinforced concrete moment-resisting frames in both directions. To develop an accurate database that closely captures the actual behavior of structures during earthquakes, it is also essential to have building selection criteria that are accurate and consistent. In particular, the database must contain RCMRF structures that have undergone significant ground shaking without any structural damage to minimize the effects of stiffness degradation (see Section 3.4). Furthermore, the selection criteria for this database must be consistent with the current design criteria of UBC-94. 
The database of this study is generated from the database and recorded motions presented in two studies: the Bertero et al. study [8] and the Bendimerad et al. study [7]. Table 3-2 shows buildings in the database, the characteristics of the moment-resisting frame structures and corresponding recorded earthquakes. This database contains the most accurate instrumental records for RCMRF structures known presently to the author of this report. The criteria for selecting these buildings are explained in detail in References [7] and [8]. The appropriate physical characteristics of each building of the database are also found in these references.

\subsubsection{Refining Criteria:}

Based on Bertero et al. and Bendimerad et al. (References [7] and [8]), the following criteria were established to refine the database of Table 3-2 while maintaining its consistency and integrity:

1. Buildings must have similar stiffness along their two principal directions. The period values obtained from instrumental records can closely approximate the fundamental period of the building if the lateral stiffiness along the two principal directions of the building are similar [8]. This implies that the refined database contains only buildings with concrete lateral moment-resisting frames in both principal directions of the building. 
2. Buildings must have filtered the earthquake motion to some extent. If the records obtained at the roof of the building are similar to the records obtained at the ground (free field), then the building did not filter any motion. The recorded motion from an instrumented building can closely capture the motion of that building during an earthquake if the fundamental frequency of the earthquake is very different from the fundamental frequency of the building [7]. If the fundamental frequency of the building is similar to the frequency of the earthquake motion, it implies that the building did not vibrate in its fundamental modes of vibration and the resulting instrumental records are of little use.

3. Buildings must be constructed with the same type of concrete. The type of concrete (lightweight aggregate versus regular aggregate) can greatly affect the mass of a RCMRF structure and therefore the fundamental period of the building. As shown in Reference [8], buildings constructed with lightweight aggregate concrete have longer period values. Mixing structures constructed with different types of concrete can significantly affect the accuracy of developing an approximate formula for calculating the period of RCMRF structures.

4. Buildings must have no reported structural damage. As mentioned in Section 3.4 , to minimize the effects of stiffness degradation on estimating the fundamental period of RCMRF structures, it is critical to have a database of 
structures that did not sustain any structural damage during the earthquake. Stiffness degradation of a concrete structure during an earthquake can reduce the stiffness of the structure and can substantially increase its post-earthquake period.

\subsubsection{Ercluded Buildings:}

Based on the refining criteria presented in Section 3.6.1, after careful review of the database presented in the Bendimerad et al.(Table 3-2), the following buildings have been excluded from this database:

1. Building 2- Holiday Inn Building in Van Nuys: This is a seven story building with ductile RCMRF in both directions. It sustained structural damage during 1971 San Fernando earthquake and as a result, a high level of stiffness degradation occurred. As explained in Sections 3.4 and 3.6.1, stiffness degradation affects the fundamental period making it difficult to evaluate the preearthquake fundamental period of a structure.

2. Building 3- Muir Medical Center in Hollywood: This building is built with lightweight concrete above the first floor (see Reference [7]). According to Bertero et al. [7], reinforced concrete structures built with lightweight aggregates tend to have longer periods than similar structures built with regular aggregates. 
A general code formula whose only variable is the building height does not accurately estimate the period values of such buildings [8].

3. Building 7- First Federal Savings Building in Pomona: This building is the shortest building of the database with a height of 30 feet (two stories). The response spectrum from instrumental records of this building was studied in detail by Bendimerad et al. in Reference [7]. According to this reference, this building filtered very little of the ground motion since the roof motion is very similar to the ground motion. The instrumental records of this building do not provide any significant information about the fundamental frequency of vibration of the building, and therefore, this building is excluded from the refined database according to the refining criterion $\# 2$, established in Section 3.6.1.

4. Building 12- Bank of California in Los Angeles: This building has a momentframe in the transverse direction and a shear wall in the longitudinal direction. The presence of a shear wall in one direction could cause the building to be significantly stiffer in that direction. This is not consistent with refining criterion \#1. It is also inconsistent with the code criterion for the use of Formula [3-1] which requires the building to have similar stiffnesses in both directions. 


\subsection{Distribution of Building Periods:}

In this section, using the refined database of Table 3-2, a probabilistic distribution for the fundamental periods of RCMRF structures is developed to account for the variation of the fundamental period in these structures. This probability density function for the period parameter, $\mathrm{T}$, will be used later in this study as input to the M-Star computer program to study the effects of uncertainties in different parameters on the UBC-94 base shear force formula.

Before developing a probability density function for the fundamental period of RCMRF structures using a linear regression analysis, it is necessary to justify the reasons for the regression analysis and to define the assumptions and the methodology.

\subsubsection{Regression Analysis- Purpose, Assumptions and Methodology:}

Figure 3-1 shows the average measured periods of buildings plotted versus the height of the buildings for the refined database of Table 3-2. A linear regression analysis is performed in order to fit a line to the sample data points of Figure 3-1. The results of the regression analysis are compared with the UBC-94 formula for calculating building

fundamental period (Formula [3-1]), and an effort is made to predict the dependence of the fundamental period of the structures on their heights by developing an appropriate 
equation for the regression line. By developing some meaningful confidence intervals for the regression line, it is possible to prescribe some band of variation for building periods. The boundaries of this band will be used to define the minimum and the maximum values of the bounded histograms for the buildings' fundamental periods.

To achieve the most unbiased estimators for the sample data of Table 3-3, the method of least squares is used for the regression analysis. The assumptions of the linear regression analysis made herein, using the least squares method, can be found on pages 401 and 402 of Reference [29]. A linear regression analysis seems to be the most appropriate since the size of the sample data is small (less than 30 ). Having a small sample of 14 points, a nonlinear regression analysis may not yield an accurate curve and may introduce undesirable, large error margins.

Using the refined data of Table 3-2 (excluded buildings are identified by *), a linear regression analysis is performed for the building fundamental period against building height, and the upper and lower limits of the $95 \%$ confidence interval are established.

In establishing the $95 \%$ confidence interval, the significance level, $\alpha$ (also called Type I Error Probability), is prescribed in advance as $a=0.05=5 \%$. This value of 0.05 is commonly prescribed in linear regression analysis of small samples (less than 30 ) to 
provide some level of tolerable error [29]. The confidence interval is then calculated from the following:

$$
P\left[T_{\text {lower }} \leq T \leq T_{\text {upper }}\right]=1-\alpha=0.95
$$

\subsubsection{Results of Reqression Analysis and Comparison with UBC:}

The upper and lower limits of the $95 \%$ confidence interval are presented in Table 3-3. Also presented in this table are the calculated period values using formula $T=0.03\left(h_{n}\right)^{3 / 4}$ of UBC-94 and formula $T=0.035\left(h_{n}\right)^{3 / 4}$ of Bendimerad et al. for comparison. Figure 31 depicts the regression analysis line with the estimated regression equation and equations fitted to the calculated upper and lower limits of the $95 \%$ confidence interval. As shown in the figure, the equation of the regression line is:

$$
T=0.008 h_{n}+0.5
$$

and the equations of upper and lower limits of the confidence interval are:

$$
T=1.35 e^{0.004 h_{m}}
$$

and,

$$
T=0.87 \ln \left(h_{n}\right)-3.22
$$


respectively. In these equations, $T$ is the fundamental period of the building in seconds and $h_{n}$ is the height of the building in feet.

From Figure 3-1 it is observed that the estimated lower limit of the $95 \%$ confidence interval varies significantly from the current UBC formula. Figure 3-1 exhibits that the current UBC line is conservative in comparison to the least squares line fitted through the data. However, the current UBC line is unconservative in comparison to the lower limit of the $95 \%$ confidence interval.

It should be stated that the current UBC line and the lower limit of the $95 \%$ confidence interval are not comparable directly because it is unclear what type of confidence limits were used to establish the current UBC line. To make a comparison between these two lines, an attempt was made to approximate a confidence limit for the current UBC line. Figure 3-2 depicts the upper and lower limits of the $70 \%$ confidence interval using the refined data of Table 3-2. This figure shows that the current UBC line, for most part, seems to be close to the lower limit of the $70 \%$ confidence interval. However, for the purpose of this study, as mentioned in Section 3.7.2, a confidence interval of $95 \%$ is chosen since it is commonly prescribed for linear regression analysis of small samples (less than 30 ) to justify some meaningful indication of error. 
Based on the analysis of the data, there is potential for fundamental periods of RCMRF structures to be lower than the current UBC line. Formula $T=0.87 \ln \left(h_{n}\right)-3.22$ for the lower limit of the $95 \%$ confidence interval presented herein, results in lower period values than the current UBC formula $T=0.03\left(h_{n}\right)^{3 / 4}$. This is significant because lower periods result in higher base shears for RCMRF structures. For example, for a 100 foot RCMRF structure, the UBC-94 formula yields a period of 1.11 seconds, and Formula [3-6] yields a period of 0.79 seconds. This translates to a significant design base shear force increase of $21 \%$ using Formula [3-6] assuming all other parameters are the same.

From the results of the linear regression analysis of Table 3-3, a normal distribution for the fundamental period of each building will be developed in Chapter 5. Generated bounded frequency histograms will be used as one of the inputs for M-Star program in order to evaluate the effects of the uncertainty in the building's fundamental period on the base shear formula of UBC-94. The lower and the upper bounds of each histogram are the lower and the upper $95 \%$ confidence limits, respectively.

\subsection{Summary:}

Current code practice for estimating the fundamental period of a RCMRF structure, the groundwork and the methodology of the current practice, and the databases of the previous work were discussed. A procedure, consistent with the UBC-94 criteria, for 
refining the database of the Bendimerad, Shah, and Hoskins study [7] has been proposed, and the refined database has been presented based on this procedure. Using the method of least squares, a linear regression analysis was performed on the refined database and the upper and lower limits of the $95 \%$ confidence interval were estimated. The regression analysis line was then compared with the UBC-94 formula. To make a comparison between these two lines, an attempt was made to approximate a confidence limit for the current UBC line. The results suggest that the current UBC line, for most part, seems to be close to the lower limit of the $70 \%$ confidence interval. From the results of the regression analysis, a method of generating normal distributions to represent the variation in the fundamental periods of buildings was proposed. In addition to the assumptions made for the linear regression analysis, it is further assumed that the heights of buildings, as built, are the same as appear on the design drawings. The heights of buildings were not measured. 
Table 3-1

Data Set of Reinforced Concrete Frame Structures Used by Gates and Foth (From Reference [8] - Copied with permission)

\begin{tabular}{|c|c|c|c|c|c|c|}
\hline $\begin{array}{l}\text { ID } \\
\text { No }\end{array}$ & Name \& Address & $\begin{array}{l}\text { Height, } \\
\text { (feet) }{ }^{2}\end{array}$ & $\begin{array}{l}\text { No. of } \\
\text { Stories }\end{array}$ & $\begin{array}{c}\mathbf{K}^{3} \\
\text { Value }\end{array}$ & $\begin{array}{c}\text { Mulhem \& } \\
\text { Maley } \\
\text { Classification 2 }\end{array}$ & Comments \\
\hline 1 & $\begin{array}{l}\text { Holiday Inn, } 824 \\
\text { Orion St }\end{array}$ & $66 / 0$ & $7 / 0$ & 0.67 & $\mathrm{RC}(\mathrm{FP})$ & $\begin{array}{l}\text { Analyzed by } \\
\text { Blume \& Assoc. }\end{array}$ \\
\hline 2 & $\begin{array}{l}\text { Valley Presbyterian } \\
\text { Hospital, } 15107 \\
\text { Vanowen Blvd. }\end{array}$ & $68 / 0$ & $7 / 0$ & - & $\mathbf{R C}$ & Circular Building \\
\hline 3 & $\begin{array}{l}\text { Bank of California, } \\
12250 \text { Ventura } \\
\text { Blvd. }\end{array}$ & $159 / 0$ & 12 & 1.0 & $\mathrm{RC}(\mathrm{MR})$ & $\begin{array}{l}\text { Analyzed by } \\
\text { Blume \& Assoc. }\end{array}$ \\
\hline 4 & $\begin{array}{l}\text { Hilton Hotel, } \\
15433 \text { Ventura } \\
\text { Blvd. } \\
\end{array}$ & $124 / 0$ & $13 / 0$ & 0.67 & $\mathbf{R C}$ & $\begin{array}{l}\text { No information is } \\
\text { available }\end{array}$ \\
\hline 5 & $\begin{array}{l}\text { Sheraton Universal, } \\
\text { 3838 Lankershim }\end{array}$ & $184 / 15$ & $19 / 1$ & 0.67 & RC (DMR) & $\begin{array}{l}\text { Analyzed by } \\
\text { Blume \& Assoc. }\end{array}$ \\
\hline 6 & Muir Medical Ctr. & $124 / 9$ & $11 / 1$ & 0.67 & $\mathbf{R C}$ & $\begin{array}{l}\text { Analyzed by } \\
\text { Conard \& Assoc. }\end{array}$ \\
\hline 7 & $\begin{array}{l}\text { Holiday Inn, } 1760 \\
\text { North Orchid. }\end{array}$ & $205 / 0$ & $22 / 0$ & 0.67 & $\mathbf{R C}$ & $\begin{array}{l}\text { No information is } \\
\text { available }\end{array}$ \\
\hline 8 & $\begin{array}{l}1800 \text { Century Park } \\
\text { E., Century City }\end{array}$ & $224 / 37$ & $16 / 3$ & 1.0 & RC (DMR) & Tubular Structure \\
\hline 9 & $\begin{array}{l}\text { Wilshire Christian } \\
\text { Towers, } 616 \\
\text { Normandie St. }\end{array}$ & $152 / 0$ & $16 / 1$ & 0.67 & $\mathrm{RC}(\mathrm{MR})$ & $\begin{array}{l}\text { No information is } \\
\text { available }\end{array}$ \\
\hline 10 & $\begin{array}{l}\text { Wilshire Square } \\
\text { One, } 3345 \text { Wilshire } \\
\text { Blvd. }\end{array}$ & $165 / 29$ & $12 / 3$ & 1.0 & RC (MR) & Tubular Structure \\
\hline 11 & 533 South Fremont & $119 / 12$ & $11 / 0$ & 1.0 & $\mathrm{RC}(\mathrm{MR})$ & Tubular Structure \\
\hline 12 & $\begin{array}{l}\text { Mohn Olympic, } \\
1625 \text { Olympic } \\
\text { Blvd. }\end{array}$ & $137 / 0$ & $10 / 0$ & - & $\mathrm{RC}$ & $\longrightarrow$ \\
\hline 13 & 120 Robertson & $118 / 19$ & $9 / 2$ & 1.0 & $\mathrm{RC}(\mathrm{SW})$ & $=$ \\
\hline 14 & $\begin{array}{l}\text { Holiday Inn, } 1640 \\
\text { Marengo }\end{array}$ & $66 / 0$ & $7 / 0$ & 0.67 & RC(FP) & $\begin{array}{l}\text { Analyzed by } \\
\text { Blume \& Assoc. }\end{array}$ \\
\hline
\end{tabular}

\footnotetext{
${ }^{1}$ Above/Below Grade

${ }^{2}$ RC: Reinforced Concrete; MR: Moment Resisting Frame; DMR: Ductile Moment Resisting Frame; FP: Flate Plate; SW: Shear Wall.

${ }^{3}$ See Formula [2-4]
} 
Table 3-2

Refined Database of RCMRF Structures: Characteristics and Corresponding Recorded Earthquakes of Bendimerad et al. Study (From Reference [7] - Copied with permission)

\begin{tabular}{|c|c|c|c|c|c|}
\hline Bidg & Name & Location & Stories & Earthquake & Comments \\
\hline 1 & Holiday Inn & Hollywood & 22 & San Femando, & Ductile MRF (both dir.). \\
\hline $2^{*}$ & Holiday $\operatorname{Inn}$ & $\begin{array}{l}\text { Van Nuys, } \\
\text { CA. }\end{array}$ & 7 & $\begin{array}{l}\text { San Fernando, } \\
1971\end{array}$ & $\begin{array}{l}\text { Ductile MRF (both dir.), } \\
\text { slight structural damage }\end{array}$ \\
\hline $3^{*}$ & $\begin{array}{l}\text { Muir Medical } \\
\text { Center. }\end{array}$ & $\begin{array}{l}\text { Hollywood, } \\
\text { CA. }\end{array}$ & 11 & $\begin{array}{l}\text { San Fernando, } \\
1971\end{array}$ & $\begin{array}{l}\text { Reinforced concrete Ductile } \\
\text { MRF }\end{array}$ \\
\hline 4 & $\begin{array}{l}\text { Sheraton } \\
\text { Universal }\end{array}$ & Los Angeles & 19 & $\begin{array}{l}\text { San Fernando, } \\
\text { Whittier }\end{array}$ & $\begin{array}{l}\text { Lightweight concrete Ductile } \\
\text { MRF, Nonstructural damage } \\
\text { during San Fernando }\end{array}$ \\
\hline 5 & Holiday Inn & Los Angeles & 7 & San Fernando, & Ductile MRF in both dir. \\
\hline 6 & Sears Warehouse & Los Angeles & 5 & Whittier, 1987 & Ductile perimeter frame \\
\hline $7^{*}$ & $\begin{array}{l}\text { First Federal } \\
\text { Savings }\end{array}$ & Pomona, CA. & 2 & Whittier, 1987 & $\begin{array}{l}\text { Ductile perimeter frame } \\
\text { (both directions) }\end{array}$ \\
\hline 8 & Bay Hill Office & San Bruno & 6 & $\begin{array}{l}\text { Loma Prieta, } \\
89\end{array}$ & Ductile MRF in both dir. \\
\hline 9 & $\begin{array}{l}\text { Pacific Park } \\
\text { Plaza }\end{array}$ & $\begin{array}{l}\text { Emeryville, } \\
\text { CA. }\end{array}$ & 30 & $\begin{array}{l}\text { Loma Prieta } \\
1989\end{array}$ & $\begin{array}{l}\text { 3-rectangular wings } \\
\text { connected by central core. } \\
\text { Ductile MRF }\end{array}$ \\
\hline 10 & $\begin{array}{l}\text { Parking } \\
\text { Structure I }\end{array}$ & $\begin{array}{l}\text { Stanford } \\
\text { University }\end{array}$ & 4 & $\begin{array}{l}\text { Loma Prieta, } \\
1989\end{array}$ & $\begin{array}{l}\text { Ductile MRF (both } \\
\text { directions) }\end{array}$ \\
\hline 11 & Hilton Hotel & $\begin{array}{l}\text { Sherman } \\
\text { Oaks, CA. }\end{array}$ & 13 & $\begin{array}{l}\text { San Fernando, } \\
1971\end{array}$ & $\begin{array}{l}\text { Ductile MRF (both } \\
\text { directions), Ductility charact. } \\
\text { could not be assessed }\end{array}$ \\
\hline $12^{*}$ & $\begin{array}{l}\text { Bank of } \\
\text { California }\end{array}$ & Los Angeles & 12 & $\begin{array}{l}\text { San Fernando, } \\
1971\end{array}$ & $\begin{array}{l}\text { MRF (both directions), } \\
\text { Shear walls up to third floor } \\
\text { in longitudinal direction }\end{array}$ \\
\hline 13 & $\begin{array}{l}\text { Tishman Airport } \\
\text { Center }\end{array}$ & Los Angeles & 14 & $\begin{array}{l}\text { San Fermando, } \\
1971\end{array}$ & $\begin{array}{l}\text { MRF (both directions), } \\
\text { Tubular Structure } \\
\end{array}$ \\
\hline 14 & $\begin{array}{l}\text { Wilshire } \\
\text { Coronado } \\
\end{array}$ & Los Angeles & 13 & $\begin{array}{l}\text { San Fernando, } \\
1971\end{array}$ & MRF (both directions) \\
\hline 15 & $\begin{array}{l}\text { Brentwood } \\
\text { Square }\end{array}$ & Los Angeles & 9 & $\begin{array}{l}\text { San Fernando, } \\
1971\end{array}$ & MRF (both directions) \\
\hline 16 & $\begin{array}{l}\text { Hollywood } \\
\text { Storage }\end{array}$ & Hollywood & 14 & Whittier, 1987 & MRF (both directions) \\
\hline 17 & Union Bank Bldg. & $\begin{array}{l}\text { Sherman } \\
\text { Oaks } \\
\end{array}$ & 13 & Whittier, 1987 & MRF (both directions) \\
\hline 18 & IBM Bldg. 012 & San Jose & 5 & $\begin{array}{l}\text { Morgan Hill, } \\
1984\end{array}$ & $\begin{array}{l}\text { MRF (both directions), } \\
\text { Seismic retrofitted in } 1986\end{array}$ \\
\hline
\end{tabular}

* These buildings are not used in this study (see Section 3.6) 
Table 3-3

Regression Analysis Results for Average of Measured Periods in both Directions of the Refined Database

\begin{tabular}{|c|c|c|c|c|c|c|}
\hline $\begin{array}{l}\text { Bldg } \\
\text { No. }\end{array}$ & $\begin{array}{l}\text { Height } \\
\text { Above } \\
\text { Grade } \\
\text { (feet) }\end{array}$ & $\begin{array}{l}\text { Average of } \\
\text { Measured } \\
\text { Periods in both } \\
\text { Directions } \\
\text { (seconds) }\end{array}$ & $\begin{array}{l}\text { Calculated } \\
\text { Period } \\
\text { Using } \\
\mathrm{T}=0.03 \mathrm{~h}_{\mathrm{r}}^{3 / 4} \\
\text { (seconds) }\end{array}$ & $\begin{array}{l}\text { Calculated } \\
\text { Period } \\
\text { Using } \\
\mathrm{T}=0.035 \mathrm{~h}_{\mathrm{n}}^{3 / 4} \\
\text { (seconds) }\end{array}$ & $\begin{array}{l}\text { Lower Limit } \\
\text { of } 95 \% \\
\text { Confidence } \\
\text { Interval for T } \\
\text { (seconds) }\end{array}$ & $\begin{array}{l}\text { Upper Limit } \\
\text { of } 95 \% \\
\text { Confidence } \\
\text { Interval for T } \\
\text { (seconds) }\end{array}$ \\
\hline 1 & 205 & 2.05 & 1.63 & 1.90 & 1.46 & 2.86 \\
\hline 4 & 184 & 2.2 & 1.50 & 1.75 & 1.34 & 2.63 \\
\hline 5 & 66 & 1.05 & 0.69 & 0.81 & 0.36 & 1.71 \\
\hline 6 & 119 & 1.35 & 1.08 & 1.26 & 0.88 & 2.05 \\
\hline 8 & 78 & 1.1 & 0.79 & 0.92 & 0.49 & 1.78 \\
\hline 9 & 300 & 2.8 & 2.16 & 2.52 & 1.92 & 3.92 \\
\hline 10 & 48 & 0.9 & 0.55 & 0.64 & 0.17 & 1.62 \\
\hline 11 & 124 & 1.35 & 1.11 & 1.30 & 0.92 & 2.08 \\
\hline 13 & 160 & 1.7 & 1.35 & 1.57 & 1.19 & 2.39 \\
\hline 14 & 166 & 2.15 & 1.39 & 1.62 & 1.23 & 2.45 \\
\hline 15 & 120 & 1.35 & 1.09 & 1.27 & 0.89 & 2.05 \\
\hline 16 & 149 & 1.55 & 1.28 & 1.49 & 1.12 & 2.29 \\
\hline 17 & 188 & 2.1 & 1.52 & 1.78 & 1.36 & 2.67 \\
\hline 18 & 65 & 0.83 & 0.69 & 0.80 & 0.35 & 1.71 \\
\hline
\end{tabular}

${ }^{1}$ From Bendimerad et al. (Reference [7] - Copied with permission) 
Figure 3-1

Comparison of the UBC-94 Period Estimation Formula with Linear Regression Line for $T$ from Instrumental Records

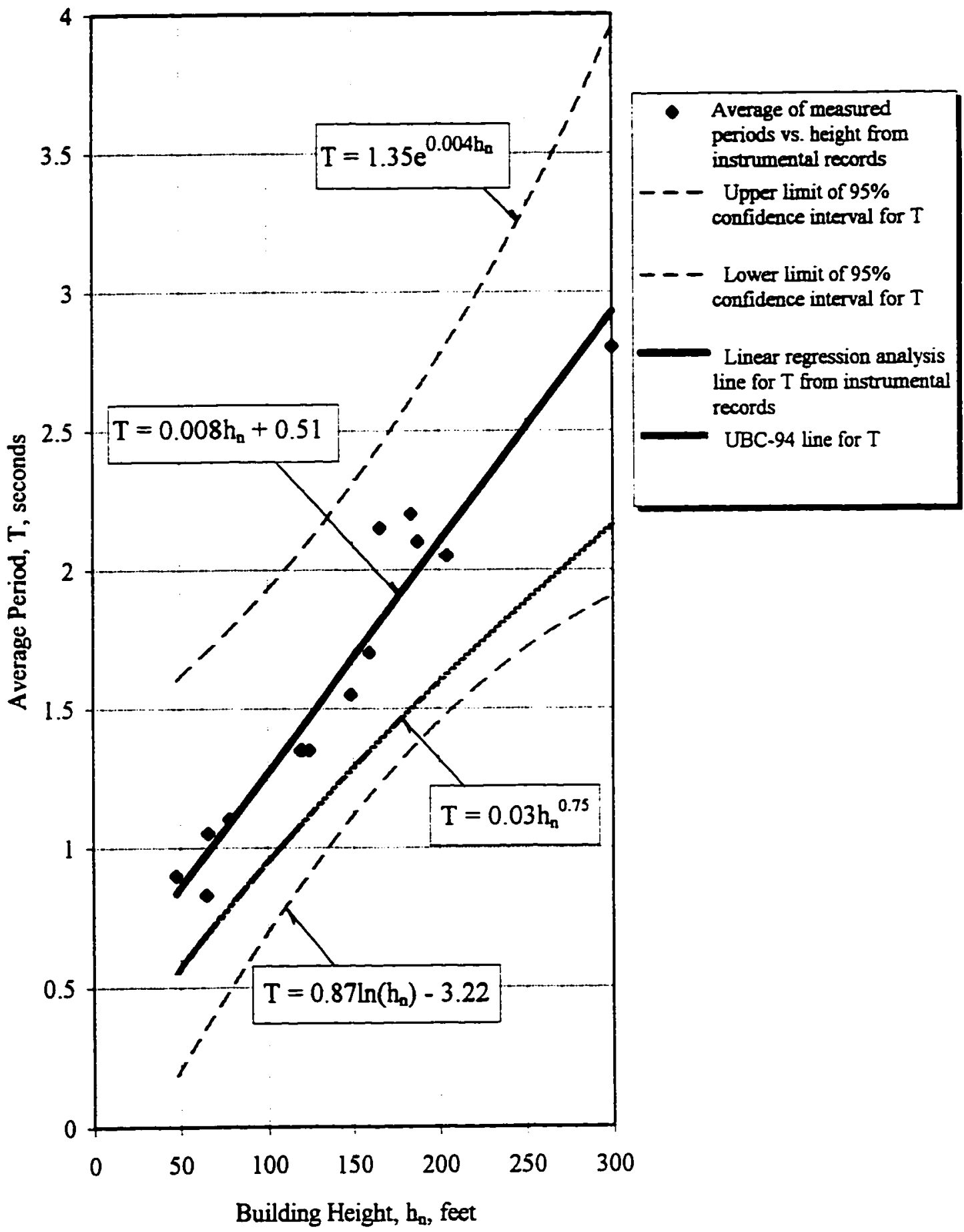


Figure 3-2

Comparison of $70 \%$ Confidence Interval Limits with the UBC-94 Feriod Estimation Formula

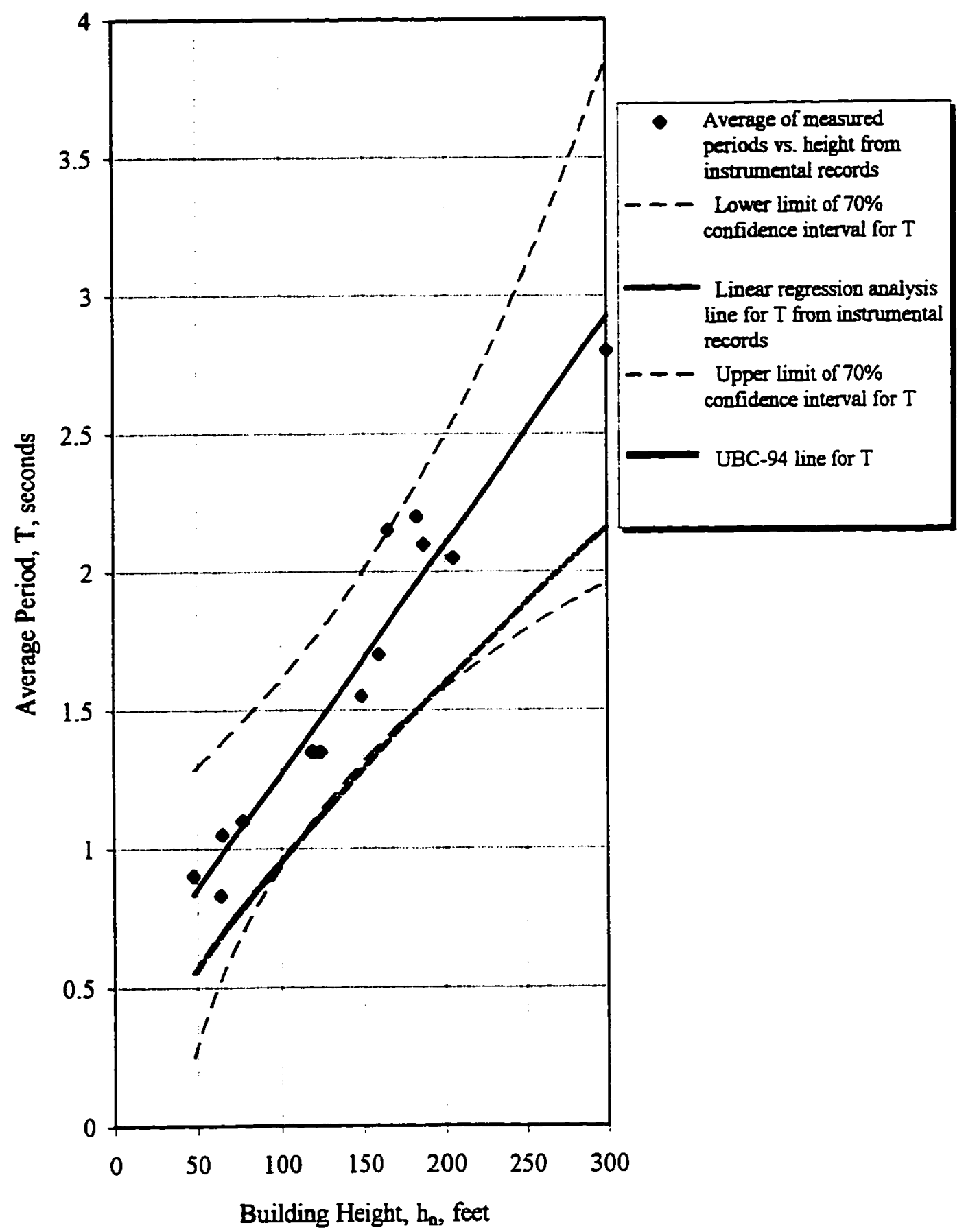




\section{Chapter 4}

\section{STRUCTURAL SYSTEM FACTOR, $R_{w}$ AND DUCTILITY DEMAND}

\subsection{Introduction:}

One of the most controversial numerical coefficients used in the base shear force formula of UBC-94 is $R_{w}$. Since its introduction in the SEAOC 1988 Blue Book, it has been the subject of numerous discussions and publications and a few analytical studies. Some of these studies and publications can be found in References [25], [13], and [39].

In the calculations of the base shear force used in the design of a multi-story building, the maximum value of $R_{w}$ can vary significantly from 4 to 12 , depending on the type and configuration of the lateral load resisting system of the structure. Table 16-N of UBC-94 specifies maximum values of $R_{w}$ which the designer can use for the structural system under consideration. For ease of reference, Table 16-N of UBC-94 is presented in this study as Table 4-1 at the end of Chapter 4. $R_{w}$ is perhaps one of the most significant coefficients in the base shear formula since its large variation plays a major role in the value of the design shear force of the building. $R_{w}$ is also called "the system quality factor" (Reference [43]), and it is an empirical parameter. In this study, the $R_{w}$ coefficient will be referred to as the "structural system factor" to be consistent with UBC-94 definitions of $R_{w}$. 
In this chapter the structural system factor, $R_{w}$, is discussed in detail. The UBC and the Blue Book definitions of $R_{w}$ are explored, and a ductility demand design approach based on the 1991 Englekirk approach [13] is presented. Similar to Chapter 3, a general overview of the previous work is presented and references are given. At the end of the chapter, a methodology for developing probability distributions for structural system factors, $R_{w}$, corresponding to different ductility factors are developed. Since the structural system factor, $R_{w}$, is discussed more extensively in the 1990 Blue Book than in the UBC-94, most of the discussions of this section are based on the assumptions and recommendations presented in the Blue Book.

\subsection{Structural System Factor, $R_{w}$ and Current Code Approach:}

In the SEAOC Blue Book [43], the structural system factor, $R_{w}$, for a given structural system and material, is defined as a measure of the ability of the structural system to sustain cyclic inelastic deformation without collapse. The 1990 Blue Book commentary states that, "the $R_{w}$ system factor has been introduced to provide a physical concept of system performance for use in the base shear format" [43]. As such, it enters into the denominator of the design base shear formula (see Formula [2-1]) so that design loads decrease for systems with large inelastic deformation capabilities [43]. The values of $R_{w}$ have been assigned according to the relative capabilities of building systems to provide energy dissipation in the inelastic range [43]. The Blue Book acknowledges that, "both 
new knowledge on performance and the development of new systems required the more extensive and detailed description of systems and assignment of $R_{w}$ values" [1990, Appendix 1E2a- $\left.R_{w}\right]$. The SEAOC commentary also recognized that the assigned $R_{w}$ values periodically must be reviewed as earthquake performance is observed and more data on material and system performance becomes available.

In the determination of $R_{w}$, the following characteristics were considered by the SEAOC Seismology Committee [1990 Blue Book, Appendix 1E2a- $R_{w}$ ]:

- observed system performance,

- level of inelastic response capability,

- possibilities of vertical load system failure,

- lateral force system redundancy, and

- multiplicity of lines of defense, such as backup frames.

However, much more research is needed to fully justify the designation of a single parameter, $R_{w}$, to account for all of the above characteristics and to describe the complex interrelations between them. The values of $R_{w}$ for categories of systems defined in Table 16- $\mathrm{N}$ are essentially empirical. These values are derived by reducing the $\mathrm{K}$ values (see Section 2.3 for $\mathrm{K}$ values) of previous code editions by a factor of $1 / 8$ and then taking the reciprocal. 
As presented in the Blue Book, $R_{w}$ is a "catch all" parameter that accounts for observed system performance, level of inelastic response capability, possibilities of vertical load system failure, lateral force system redundancy, and engineering judgment ([43]-Appendix 1E2a- $\left.R_{w}\right)$. As discussed by Osteraas and Krawinkler [39], little justification has been provided to support the numerical values of $R_{w}$, and numerical values are largely subjective, based on "engineering judgment". Similar structural systems, but with different relative stiffnesses and ductilities, are assigned the same values of $R_{w}$. The SEAOC (or UBC) $R_{w}$ approach does not recognize any variation in performance within a structural load resisting system category. For example, as shown in Table 4-1, all concrete special moment-resisting frames (SMRF) with a regular configuration (see Section 2.1 for definition), regardless of height, stiffness or frame geometry and redundancy, are assigned the same value of $R_{\mathrm{w}}=12$.

The Blue Book also identifies two major aspects of structural behavior that account for satisfactory performance of structures designed to a reduced level of elastic design using the $R_{w}$ approach: total system resistance capacity and inelastic response capability ([43]Appendix 1E2a- $R_{w}$ ). Again, as shown by Osteraas and Krawinkler [39], both total system resistance capacity (or system strength) and inelastic response capability (which is intended to be reduced to a level of elastic design in the UBC/SEAOC approach) are not only period and system dependent, but highly dependent upon the configuration of a 
particular system. In contrast, the current code approach does not assign a value of $R_{w}$ for a system according to the period and configuration of that particular system.

\subsection{Elastic Design and Susceptibility to Damage:}

Although it is possible to design a structure to resist severe lateral earthquake loads elastically, economic factors usually dictate a system designed to dissipate energy through inelastic deformation within tolerable limits [3]. Current earthquake-resistant design is primarily focused on safety and reducing the possibility of extensive damage to the structure rather than preventing damage occurrence [38]. The current code elastic response approach provides a poor measure of susceptibility to damage because the damage done to a structure during strong motion excitation depends primarily on the energy transmitted to and absorbed by the structure during inelastic cycling [38]. According to O'Connor and Ellingwood (1987), due to the dynamic nonlinear response of structures during strong earthquakes, it is difficult to prescribe a limit state based on the concept of strength of a member at some critical section. Instead, the limit states for earthquake design should be related to the damage done to the building, and must take overall system behavior into account. Currently, SEAOC and its Vision 2000 committee are in the process of developing performance-based seismic design standards for earthquake design. Such an approach will consider damage control and functionality of structures as well as life safety [41]. 
In seismic design of structures the designer must cautiously consider the structural damage due to the seismic load reversal effects. During strong ground motion, if a structure undergoes repeated cycles of inelastic action, it generally sustains more damage than if it is subjected to a single large load reversal. The total amount of plastic deformation sustained by a structure (and energy dissipation) depends on the duration of strong ground motion as well as on peak ground motion intensity [38]. Structural damage at the material level is closely related to the extent of inelastic deformations. This is particularly true for reinforced concrete moment-resisting frame structures, which are sensitive to stiffness degradation. Recurrent plastic reversals in parts of structural components can also create conditions causing failure due to low-cycle fatigue [33]. Thus, the designer must carefully consider the duration of the earthquake ground motion as well as the frequency content of the loading.

\subsection{Ductility Factor and System Ductility:}

Before developing a relationship between system ductility and $R_{w}$ in Section 4.5 , It is essential to explore different definitions of ductility factor and system ductility for elastic and inelastic systems. 
Several definitions of ductility factor for single degree of freedom systems can be found in Reference [30]. The following definitions of ductility factor are of the interest to this study:

$$
\begin{aligned}
& \mu=\left(X_{\max } / X_{y}\right)>I \quad \text { (Displacement ductility factor) } \\
& \mu=\left(X_{\max } \text { equevalent } / X_{y}\right)>I \quad \text { (Normalized hysteretic energy ductility factor) } \\
& \mu=\left[\left(X_{\max }^{+}+X_{\max }^{-}\right) / X_{y}\right]-X_{y} \quad \text { (Cyclic ductility factor) }
\end{aligned}
$$

In these formulas, $X_{\max }$ is the maximum displacement of the system and $X_{y}$ is the displacement of the system at yielding. Formula [4-2] is based on the relationship between ductility and hysteretic energy. This definition of ductility factor is numerically equal to the ductility of a monotonically loaded elastic-perfectly-plastic system (Figure 4-1a) that dissipates the same amount of hysteretic energy and has the same yield strength and initial stiffness as the actual inelastic system (Figure 4-1b). Formula [4-3] is applicable to a system that has undergone several cycles. As shown in Figure 4-Ic, $X_{\text {max }}^{+}$is the maximum positive displacement, $X_{\text {max }}^{-}$is the maximum negative displacement, and $X_{y}$ is the yield displacement. 
Velkov [46] has shown that there are explicit formulas for bilinear systems relating the energy dissipation properties of the system and the ductility factor. He showed that the energy dissipation properties of a structure are a function of hardening ratio and ductility factor.

O'Connor and Ellingwood [38] also used the ductility demand definition given by Formula [4-1], but with different notation as, "the simplest indicator of the level of nonlinear structural response defined as the ratio of the maximum displacement of an inelastic system to its yield displacement." They also defined ductility factor as, "a descriptor of the single largest plastic excursion undergone by the system during excitation." This definition is also used by Newmark and Hall in a 1973 study [37].

In 1992, Englekirk [13] used another approach to define the ductility of a system to analyze the efficiency of the U.S. seismic design codes and practice. Englekirk defined system ductility as, "the ratio of the spectral acceleration of an elastic system, $S_{a r}$, to the design or yield level spectral acceleration of a comparable ductile (inelastic) system, $S_{a y}$ " This definition is represented in the form of Formula [4-4].

$$
\mu=\frac{S_{\alpha}}{S_{\sigma y}}
$$


Englekirk used this formula as a foundation for relating the structural system factor, $R_{\mathrm{w}}$, and the design ductility demand (or system ductility), $\mu$ Formula [4-4] has been shown to be valid for systems whose fundamental period is in excess of about 0.6 seconds [13]. This formula is based on the assumption of equating the maximum relative displacement of the design response spectrum of an inelastic system (or ductile system since, by definition, the ductility of an elastic system is assumed to be less than or equal to one) to the maximum relative displacement of a comparable elastic system. This assumption is originally based on Newmark's and Veletsos' attempts in 1960 to relate elastic and inelastic response of structures with small damping (5\% or less) [36]. Formula [4-4] will be discussed in more detail in Section 4.5.2.

In summary, the above definitions of ductility factor indicate that the energy absorption capacity of a structure is directly related to the ductility factor and therefore the ductility demand of that structure. Higher ductility demand, by definition, increases the energy absorption capacity of the structure and makes the structure able to withstand higher levels of excitation. By developing a rational relationship between ductility demand and other characteristics of the structure and by defining a reasonable value for ductility demand for a particular structure, the engineer could design a building for a particular level of performance under seismic loading. Reciprocally, the expected level of performance of a particular design (seismic demand) could be defined from a design response spectrum for a given site and the expected yield level for that particular design. 
For the purpose of earthquake design, structural engineers should clearly distinguish between the differences in the definitions of system ductility for inelastic and elastic systems, and material ductility. Although ductility for a structural system can be a function of material ductility, there are several other important factors that greatly contribute to the ductility of a structural system. Redundancy, reliability of as-built performance, inelastic load-deformation behavior, and changed damping and period modification with deformation, all affect the capability of a structural system to resist severe earthquake ground motion without collapse ([43]-Appendix 1E2a- $\left.R_{w}\right]$. Different definitions of system ductility presented in this chapter do not intend to represent the same definition as the ductility of the materials given in any mechanics of materials text book such as Reference [19]. Rather, these definitions of ductility are used to describe the ability of a structural system to displace beyond its yield displacement into an inelastic range without collapse during severe earthquake ground motion.

\subsection{Development of System Ductility as a Function of $R_{w}$ :}

Several challenges and complexities were encountered while developing a relationship between the system ductility and $R_{w}$ for the database of this study. In an attempt to develop probabilistic distributions for the values of $R_{w}$ from instrumental records of the buildings of Table 3-3, a band of variation for $R_{w}$ must be defined. This study aims at the evaluation of RCMRF structures and all the buildings of this study are of this type. There 
is no variation of $R_{\text {w }}$ defined within this sub-system in the UBC. Likewise, it is certainly not possible to estimate any rational band of variation of $R_{w}$ for the structures with the same lateral load resisting frame system from instrumental records because $R_{w}$ is an empirical parameter and highly subjective. Instrumental records do not provide any information regarding a reduction factor such as $R_{w}$, which is assumed to be the same for the buildings of a particular structural system. Consequently, the main challenge is to develop a rational approach to relate inelastic ductility demand with other building characteristics of the database of Table 3-3. Examples of some of these characteristics are the building period and the design spectral acceleration of the system.

For each building of Table 3-3, the average of the periods in both directions of the building is known from instrumental records, and the design spectral acceleration can be defined from the maximum probable earthquake (MPE) ground motion. By developing an approximate relationship between ductility demand, design spectral acceleration, building period, and $R_{w}$, it is possibie to define some band of variation for $R_{w}$. The rest of this chapter is devoted to developing such an approximate relationship.

\subsubsection{Previous Attempts:}

Several attempts have been made by researchers and engineers to relate seismic demand and the desired ductility capacity of a structure to a structural system factor, such as $R_{w}$, 
that could account for the inelastic behavior of the structure under severe ground motions. For example, Hadidi-Tamjid [24] used a statistical approach to relate the ductility demand and period values using 15 Western U.S. ground motion records. Osteraas and Krawinkler [39] published a report characterizing inelastic demand and ductility considerations in seismic design for structures damaged in the 1985 Mexico earthquake. This report has been referred to several times throughout this study. Austin, Pister and Mahin ([4], [5], and [6]) also published several papers on testing a methodology for quantifying the optimal probabilistic limit states of seismic-resistant steel frames.

All of these studies acknowledge the fact that since for a building with several stories, quantities such as seismic demand and ductility capacity are difficult to qualitatively characterize and accurately estimate for anticipated earthquakes, the task needs much further research. There are several reasons for this difficulty, probably the most important reason lies in the difficulty of predicting the nonlinear behavior of structures during severe ground motions (see Section 4.4 for more detail). Other difficulties are due to the uncertainty in design parameters and the complexity of earthquake motions.

\subsubsection{Appropriate Relationship:}

As mentioned in Section 4.4, Englekirk [13] explored the rationale behind the present code base shear formula to analyze the efficiency of seismic design codes. His exploration 
was found to be most appropriate for this study in developing the desired relationship between system ductility and $R_{w}$ (see Section 4-4). He used the definition of system ductility, $\mu_{2}$ as, "the ratio of the spectral acceleration of an elastic system, $S_{\alpha e}$, to the design or yield level spectral acceleration of a comparable ductile (or inelastic) system, $S_{a y}$ " (see Formula [4-4] in Section 4.5). After rearrangement, Formula [4-4] can be written as:

$$
S_{a y}=\frac{S_{a e}}{\mu}
$$

Thus, the design inelastic acceleration response spectra, $S_{a y}$, is equal to the design elastic acceleration response spectra, $S_{a e}$, reduced by a system ductility factor, $\mu$. Formula [4-4] describes a ratio of accelerations and requires that the acceleration expected at a site for an elastic system, $S_{\alpha e}$, be developed. Englekirk uses the maximum probable earthquake (MPE) design response spectrum of Figure 4-2 as the expected level of acceleration for a given site. This design response spectrum is developed from ground motions expected at a site whose subsurface is described as a stiff or dense soil condition (soil type $S_{1}$ ) located in the Los Angeles area, and the seismic demand of the design is assumed to be met by this spectrum. The design response spectrum of Figure 4-2 is assumed to be appropriate to describe the damage threshold for the buildings of this study since most of the buildings of this study are located in the Los Angeles area (see Table 3-3). Therefore, Figure 4-2 
establishes the elastic spectral acceleration, $S_{a e}$, that these buildings can be expected to experience. Combining Formula [4-4] and the Newtonian relationship of $F=m a$ defines the yield force for a single degree of freedom system, $F_{y}$ :

$$
F_{y}=m S_{a y}=(W / g) S_{a y}
$$

Substituting Formula [4-5] to [4-6] yields:

$$
F_{y}=\frac{S_{a c}}{\mu \cdot g} W
$$

where $S_{\alpha}$ is in terms of $g$ (acceleration of gravity - see Figures 4-2 and 4-3), $W$ is the total seismic weight of the system, and all other terms were defined previously. In addition, the base shear Formula [2-3] can also be rewritten as:

$$
V=\frac{Z(1.25 S) I}{\left(T^{23}\right) R_{w}} W
$$

To extract system ductility, $\mu$, Formulas [4-7] and [4-8] can be equated considering the following adjustments: 
1. Formula [4-8] describes the UBC code base shear associated with the initial yield of a MDOF system in terms of a yield stress level of individual members and must accordingly be factored if it is to be set equal to Formula [4-7]. As indicated in the SEAOC Blue Book, "there is a factor of about 1.4 between the allowable combined effects stress (one and one-third times allowable) and the yield or strength design basis for individual elements" [1990, Appendix 1E2a- $R_{w}$, Page 148-C]. Therefore, Formula [4-8] must be multiplied by 1.4 accordingly.

2. The spectrum of Figure 4-2 identifies the acceleration level $\left(S_{\alpha e}\right)$ expected for a SDOF system and not the base shear for a MDOF system [13]. For a typical multi-story building of fairly uniform mass and stiffness subjected to horizontal ground motion, the motion tends to excite response of a structure mainly in its first mode [10]. The modal participation factor is assumed to be 0.8 for a seven story structure to describe the mode shape for the dominant, from a base shear perspective, first mode [13]. Therefore, since all of the multi-story buildings of this study are of fairly uniform mass and stiffness, it is assumed that multiplying Formula [4-7] by a factor of 0.8 can approximately describe the modal participation and the dominant mode shape for these buildings.

Considering the adjustment factors from above, equating Formulas [4-7] and [4-8] yields: 


$$
0.8 * \frac{S_{\alpha}}{\mu \cdot g}=\frac{Z(1.25 S) I}{\left(T^{2 / 3}\right) R_{w}} * 1.4
$$

Assuming $I=1.0$ (non-essential buildings), $Z=0.4$ (seismic zone 4), and $S=1.0$ (soil type $S_{1}$ ), Formula [4-9] can be rearranged to yield an expression for $R_{w}$ of a MDOF system:

$$
R_{w}=\frac{\mu}{1.14 S_{\alpha \alpha} T^{2 / 3}}
$$

It must be mentioned that Formula [4-10] was derived previously in Reference [13], and it is rederived here in detail to clarify the rationale behind its derivation.

Formula [4-10] shows that $R_{w}$ is a function of the ductility of the structural system and is period dependent since in addition to $\mathrm{T}$, it contains the period dependent variable $S_{a c}$. This relationship also suggests that structural system factor, $R_{w}$, can be a function of the design response spectrum for a particular site, in this case, design elastic acceleration response spectrum for MPE of Figure 4-2. The dependence of the structural system factor on other buildings characteristics will be discussed more in Section 4.6 .

\subsection{Structural System Factor, $\boldsymbol{R}_{\boldsymbol{w}}$, Distributions:}

Formula [4-10] approximately describes a relationship between the building period, system 
ductility (ductility demand), and the design elastic spectral acceleration for a RCMRF structural system. This formula is used in this study mainly to prescribe some band of variation for the structural system factor, $R_{w}$, considering the ductility of the structural system.

To develop a probabilistic distribution for $R_{w}$ that describes this band of variation, several quantities must be defined. For each building of this study, the average of the periods in both directions of the building was previously defined using the procedure described in Chapter 3. Additionally, corresponding to each period, the value of the expected acceleration level for the MPE can be extracted from Figure 4-2. MPE corresponds to the ground response spectrum of a family of earthquakes that is likely to occur at a given site over some period of time. Figure 4-3 shows the extracted values of the design elastic spectral acceleration, $S_{\alpha e}$, corresponding to the values of the average periods of Table 3-3. System ductility, $\mu$, however, can't be calculated in the absence of the stiffiness properties of the buildings of the database of this study, and it must be approximated. To approximate the system ductility of RCMRF structures of this study, some background information is given in the next sections for clarification purposes.

It is well known to engineers that buildings with short periods require higher ductility demand, considering the tolerable degree of risk with regard to damage and consistent with the design philosophy ([10] and [43]). Defining the tolerable degree of damage and 
the strength level of structural systems is beyond the scope of this study. However, for the purpose of this study, it is appropriate to mention that when defining the allowable ductility demand of a particular structure subjected to the maximum probable earthquake (MPE), its overall ductility capacity should be taken into consideration [10]. During a large earthquake, the ductility demand of a structure, particularly a reinforced concrete structure, can't be met with 100 percent confidence [10]. This complication is due to the increase of strength of concrete over time (change in stiffness), change in period during and after strong earthquakes (see Chapter 3), scatter of extreme values of response for each family of earthquake excitations, and the quality of construction among other factors.

For design purposes, a typical multi-story RCMRF structure, with fairly uniform mass and stiffness distribution in both transverse and longitudinal directions and with the average period between 0.75 seconds and 2.5 seconds, has a system ductility factor that varies from 0.35 to 4.0 considering a $15 \%$ probability of exceedance ([10], [13], and [38]). However, as mentioned in Section 4.4 , defining a system ductility factor of less than one for a structural system implies that the structure will remain elastic during the earthquake excitation. To benefit from the inelastic energy absorption capacity of structures, it is more feasible to design ductile structures that behave inelastically during strong ground motions while maintaining their integrity. For this purpose, the ductility of a regular RCMRF structure is theoretically assumed to have a value of 1 to 4 . 
Figure 4-4 depicts fitted curves for the values of $R_{w}$ versus $\mathrm{T}$ for the refined database of this study using Formula [4-10]. Also shown for comparison in this figure are the UBC94 values of $R$, from Table 4-1 in the form of straight lines for reinforced concrete special moment-resisting frames (SMRF), reinforced concrete intermediate moment-resisting frames (MMRF), and reinforced concrete ordinary moment-resisting frames (OMRF). In this figure, using Formula [4-10], corresponding to different system ductilities, $\mu$, period values, $T$, and the extracted values of the design elastic spectral acceleration, $S_{a e}$, appropriate $R_{w}$ curves are presented. Four curves are identified, with each curve corresponding to a group of points with system ductility values of $1,2,3$, or 4 . Each fitted curve represents the results of a regression analysis for a particular system ductility. The formulas for these $R_{w}$ curves are of the form:

$$
R_{w}=n T^{04}
$$

where $n=3.38,6.76,10.14$, and 13.52 corresponding to system ductility of $1,2,3$, and 4 , respectively. Using Formula [4-11] and substituting a period value from Table 3-3 for each building yields a value for $R_{w}$ corresponding to the assumed level of system ductility.

Figure 4-4 shows that for RCMRF structures of this study with an assumed system ductility of $\mu=1$, the value of $R_{w}=5$ from UBC-94 for reinforced concrete OMRF structural systems is unconservative because, as shown by Formula [2-1], lower $R_{\mathrm{w}}$ results 
in higher base shears. For system ductility of $\mu=2$, the $R_{\mathrm{w}}$ values for the buildings of this study are somewhere between $\mathrm{UBC}$ values of $R_{\mathrm{w}}=5$ for reinforced concrete OMRF structural systems and $R_{w}=12$ for reinforced concrete SMRF structural systems.

When system ductility is assumed to be 3 , for buildings with periods of less than approximately 1.5 seconds, $R_{w}=12$ for reinforced concrete SMRF structural system does not seem to represent a conservative value. It appears from Figure $4-4$ that these buildings require lower structural system factors and thus, should be designed for higher base shears (see Formula [2-1]). However, for buildings with periods greater than 1.5 seconds, $R_{w}=12$ represents a conservative maximum value. For a system ductility of 4 , the $R_{w}$ value for reinforced concrete SMRF represents a conservative value for RCMRF structures of this study.

Overall, Figure 4-4 and the above discussion suggest that in order to justify the designation of values of $R_{w}$ for the design purposes of RCMRF structures, the period and the ductility of the structural system must be taken into consideration. According to UBC-94, in seismic zone 4 (where buildings of this study are located) only the use of $R_{w}=12$ is allowed for reinforced concrete SMRF structures. Figure 4-4 suggests that this value of $R_{w}=12$ is conservative for calculating the base shear forces for RCMRF structures of this study with system ductilities of 4 or with periods longer than 1.5 seconds and system ductilities above 3 . 
Based on the results of $R_{w}$ from the procedure discussed above, a uniform distribution for each value of $R_{w}$ will be developed in Chapter 5. These distributions will represent the variation of the structural system factor for the buildings of the database of Table 3-3. They will be used in Chapter 5 to form bounded frequency histograms in order to include some level of uncertainty in $R_{w}$ for the calculation of the base shear formula of UBC-94.

\subsection{Summary:}

In this chapter, the structural system factor, $R_{w}$, is discussed in detail. To explore essential aspects of $R_{w}$, the definition of the structural system factor is presented, the current UBC approach in defining this factor is clarified, and a potential refinement is discussed. It is mentioned that $R_{w}$ is basically a "catch all" parameter, and much additional research is needed to fully justify the assignment of a single value of $R_{w}$ to account for all of the roles that this single value is expected to play. It is also briefly discussed that the current code elastic design approach provides a poor measure of susceptibility of a structure to damage during the earthquake excitation. Furthermore, the ductility factor and system ductility for elastic and inelastic design of a structural system are defined in detail and several definitions are explored based on different approaches by researchers and engineers. An attempt is made in Section 4.5 to develop an approximate relationship between system ductility and $R_{w}$, and the challenges in developing such a 
relationship from instrumental records are discussed. Finally, a method of developing a uniform distribution for $R_{w}$ is proposed in Section 4.6 and the results are discussed. 


\section{Table 4-1: Structural Systems and Structural System Factors, $\boldsymbol{R}_{\boldsymbol{w}}$} From Table 16-N of UBC - Reproduced from the 1994 edition of the Uniform Building CoderM, copyright 1 1994, with the permission of the publisher, the International Conference of Building Officials)

\begin{tabular}{|c|c|c|}
\hline $\begin{array}{c}\text { Basic } \\
\text { Structural } \\
\text { Systems } 1\end{array}$ & Description of Lateral Force Resisting System & $R_{w}^{2}$ \\
\hline $\begin{array}{l}\text { 1. Bearing wall } \\
\text { system }\end{array}$ & $\begin{array}{l}\text { 1. Light-framed walls with shear panels } \\
\text { a. Wood structural panel walls for structures three stories or less } \\
\text { b. All other light-framed walls } \\
\text { 2. Shear walls } \\
\text { a. Concrete } \\
\text { b. Masonfy } \\
\text { 3. Light steel-framed bearing walls with tension-only bracing } \\
\text { 4. Braced frames where bracing carries gravity loads } \\
\text { a. Steel } \\
\text { b. Concrete } \\
\text { c. Heavy timber }\end{array}$ & $\begin{array}{l}8 \\
6 \\
6 \\
6 \\
4 \\
6 \\
4 \\
4\end{array}$ \\
\hline $\begin{array}{l}\text { 2. Building } \\
\text { frame system }\end{array}$ & $\begin{array}{l}\text { 1. Steel eccentrically braced frame (EBF) } \\
\text { 2. Light-framed walls with shear panels } \\
\text { a. Wood structural panel walls for structures three stories or less } \\
\text { b. All other light-framed walls } \\
\text { 3. Shear walls } \\
\text { a. Concrete } \\
\text { b. Masonry } \\
\text { 4. Ordinary braced frames } \\
\text { a. Steel } \\
\text { b. Concrete }{ }^{3} \\
\text { c. Heavy timber } \\
\text { 5. Special concentrically braced frames } \\
\text { a. Steel }\end{array}$ & $\begin{array}{l}10 \\
9 \\
7 \\
8 \\
8 \\
8 \\
8 \\
8\end{array}$ \\
\hline
\end{tabular}

\footnotetext{
'Basic structural systems are defined in Section 1627.6 of UBC 1994.

${ }^{2}$ See Section 1628.3 of UBC 1994 for combination of structural systems.

3 Prohibited in Seismic Zones 3 and 4.
} 
Table 4-1 (Continued): Structural Systems and Structural System Factors, $\boldsymbol{R}_{\boldsymbol{w}}$ (From Table 16-N of UBC - Reproduced from the 1994 edition of the Uniform Building Code $\mathrm{TM}$, copyrightO 1994, with the permission of the publisher, the International Conference of Building Officials)

\begin{tabular}{|c|c|c|}
\hline $\begin{array}{c}\text { Basic } \\
\text { Structural } \\
\text { Systems }\end{array}$ & Description of Lateral Force Resisting System & $R_{w}$ \\
\hline $\begin{array}{l}\text { 3. Moment- } \\
\text { resisting frame } \\
\text { system }\end{array}$ & $\begin{array}{l}\text { 1. Special moment-resisting frames (SMRF) } \\
\text { a. Steel } \\
\text { b. Concrete } \\
\text { 2. Masonry moment-resisting wall frame } \\
\text { 3. Concrete intermediate moment-resisting frames (IMRF) }{ }^{4} \\
\text { 4. Ordinary moment-resisting frames (OMRF) } \\
\text { a. Steel } 5 \\
\text { b. Concrete } 6\end{array}$ & $\begin{array}{l}12 \\
12 \\
9 \\
8 \\
6 \\
5 \\
\end{array}$ \\
\hline 4. Dual Systems & $\begin{array}{l}\text { 1. Shear walls } \\
\text { a. Concrete with SMRF } \\
\text { b. Concrete with steel OMRF } \\
\text { c. Concrete with concrete IMRF } \\
\text { d. Masonry with SMRF } \\
\text { e. Masonry with OMRF } \\
\text { f. Masonry with MMRF } \\
\text { 2. Steel EBF } \\
\text { a. With steel SMRF } \\
\text { b. With steel OMRF } \\
\text { 3. Ordinary braced frames } \\
\text { a. Steel with steel SMRF } \\
\text { b. Steel with steel OMRF } \\
\text { c. Concrete with concrete SMRF } \\
\text { d. Concrete with concrete IMRF } \\
\text { 4. Special concentrically braced frames } \\
\text { a. Steel with steel SMRF } \\
\text { b. Steel with steel OMRF }\end{array}$ & $\begin{array}{c}12 \\
6 \\
9 \\
8 \\
6 \\
7 \\
12 \\
6 \\
10 \\
6 \\
9 \\
6 \\
11 \\
6 \\
\end{array}$ \\
\hline $\begin{array}{l}\text { 5. Undefined } \\
\text { systems }\end{array}$ & See Sections 1627.8 .3 and 1627.9 .2 of the 1994 UBC & - \\
\hline
\end{tabular}

${ }^{4}$ Prohibited in Seismic Zones 3 and 4, except as permitted in Section 1632.2 of UBC 1994.

5 Ordinary moment-resisting frames in Seismic Zone 1 meeting the requirements of Section 2211.6 of UBC 1994 may use a structural system factor of 12.

6 Prohibited in Seismic Zones 2A, 2B, 3 and 4. See Section 1631.2.7 of UBC 1994. 
Table 4-2

Results of Calculated Structural System Factors, $\mathbf{R}_{\mathbf{m}}$ for RCMRF Structures with System Ductility Factors of $1,2,3$, and $4(\mu=1,2,3,4)$

\begin{tabular}{|c|c|c|c|c|c|c|c|}
\hline \multirow[t]{2}{*}{$\begin{array}{c}\text { Building } \\
\text { No. }\end{array}$} & \multirow{2}{*}{$\begin{array}{c}\text { Building } \\
\text { Height } \\
\text { (feet) }\end{array}$} & \multirow{2}{*}{$\begin{array}{c}\text { Average of } \\
\text { Measured Periods, } \\
T^{1}, \text { (seconds) }\end{array}$} & \multirow{2}{*}{$\begin{array}{c}\text { Extracted Values } \\
\text { of } S_{\alpha} \text { for MPE } \\
\text { (g's) }\end{array}$} & \multicolumn{4}{|c|}{$\begin{array}{c}\text { Results of } R_{w} \text { from } \\
R_{w}=\mu /\left(1.14 S_{x} T^{2 / 3}\right)\end{array}$} \\
\hline & & & & $\mu=1$ & $\mu=2$ & $\mu=3$ & $\mu=4$ \\
\hline 1 & 205 & 2.05 & 0.120 & 4.53 & 9.06 & 13.59 & 18.12 \\
\hline 4 & 184 & 2.2 & 0.111 & 4.67 & 9.34 & 14.02 & 18.69 \\
\hline 5 & 66 & 1.05 & 0.240 & 3.54 & 7.08 & 10.61 & 14.15 \\
\hline 6 & 119 & 1.35 & 0.190 & 3.78 & 7.56 & 11.34 & 15.12 \\
\hline 8 & 78 & 1.1 & 0.230 & 3.58 & 7.16 & 10.74 & 14.32 \\
\hline 9 & 300 & 2.8 & 0.086 & 5.13 & 10.27 & 15.40 & 20.54 \\
\hline 10 & 48 & 0.9 & 0.270 & 3.49 & 6.97 & 10.46 & 13.94 \\
\hline 11 & 124 & 1.35 & 0.190 & 3.78 & 7.56 & 11.34 & 15.12 \\
\hline 13 & 160 & 1.7 & 0.150 & 4.11 & 8.21 & 12.32 & 16.42 \\
\hline 14 & 166 & 2.15 & 0.113 & 4.66 & 9.32 & 13.98 & 18.64 \\
\hline 15 & 120 & 1.35 & 0.190 & 3.78 & 7.56 & 11.34 & 15.12 \\
\hline 16 & 149 & 1.55 & 0.160 & 4.09 & 8.19 & 12.28 & 16.37 \\
\hline 17 & 188 & 2.1 & 0.115 & 4.65 & 9.30 & 13.95 & 18.61 \\
\hline 18 & 65 & 0.83 & 0.290 & 3.42 & 6.85 & 10.27 & 13.70 \\
\hline
\end{tabular}

${ }^{1}$ From Bendimerad, Shah, and Hoskins (Reference [7] with permission) 


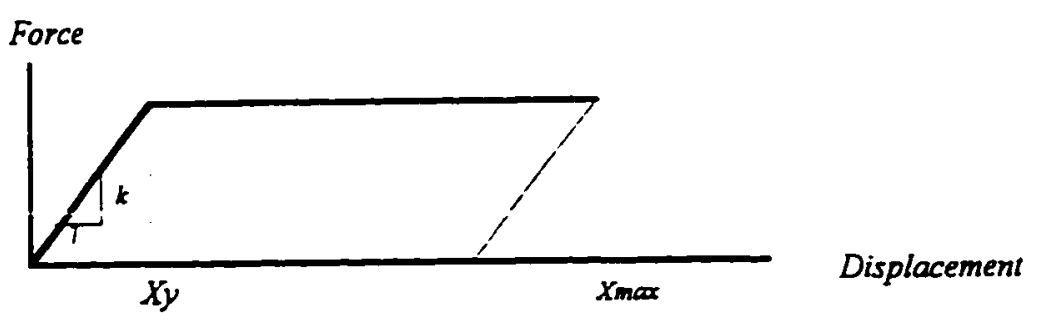

Figure 4-1a: Ductility of an Elastic-Perfectly Plastic System (from the 1979 Lashkari-Irvani [30], Copied with permission)

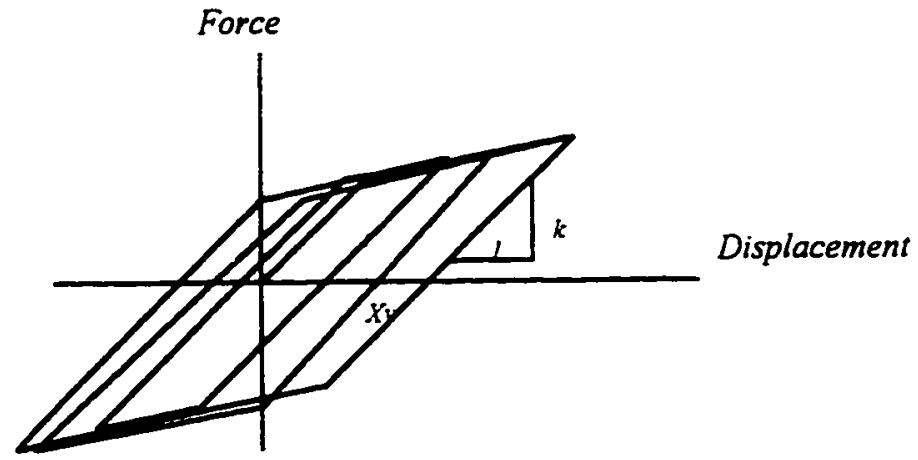

Figure 4-1b: Hysteretic Energy of an Inelastic System

(From the 1979 Lashkari-Irvani [30], Copied with permission)

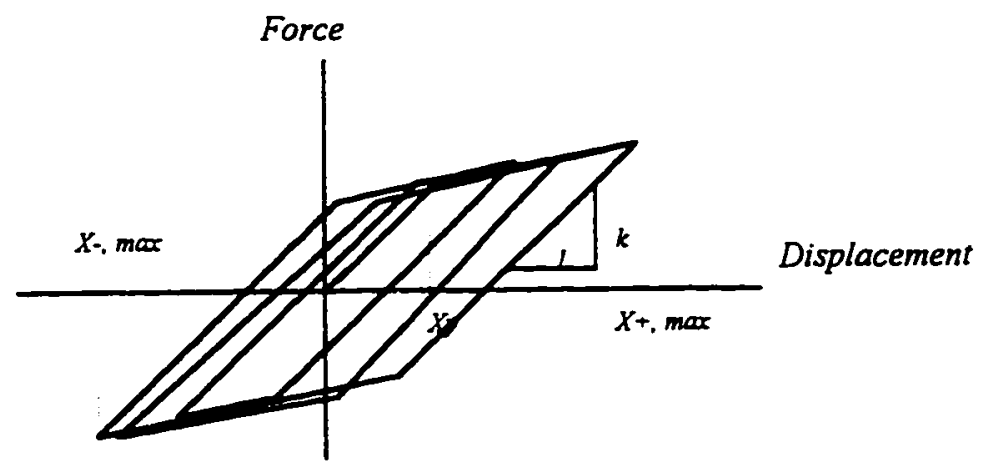

Figure 4-1c: Cyclic Ductility Factor

(From the 1979 Lashkari-Irvani [30], Copied with permission) 
Figure 4-2

Design Spectrum for Maximum Probable Earthquake (MPE) with 5\% Damping (From the 1992 Englekirk [13], Copied with permission)

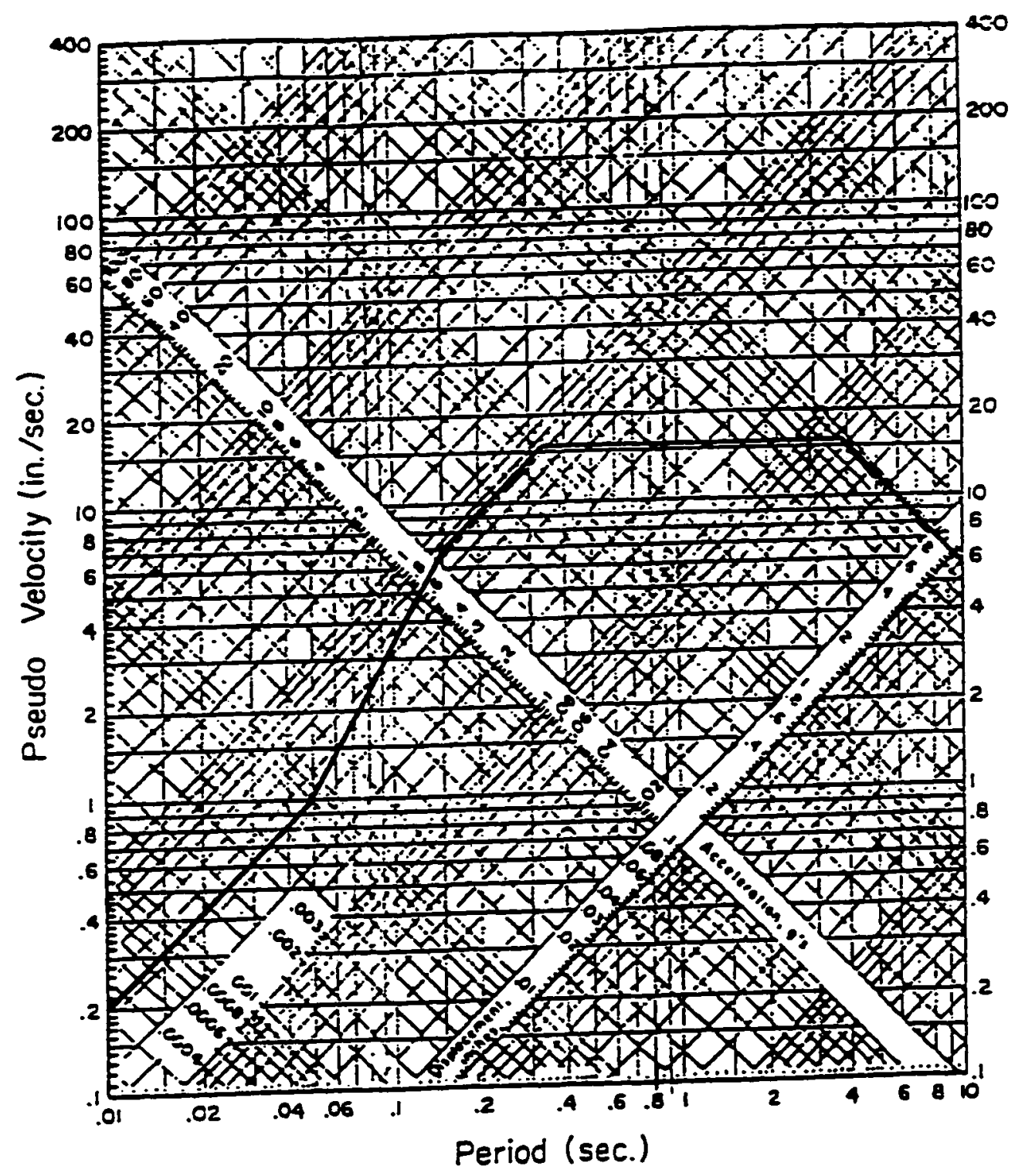


Figure 4-3

Ertracted Values of Design Elastic Spectral Acceleration, $\mathbf{S}_{\mathrm{w}}$ for MPE from Figure 4-2

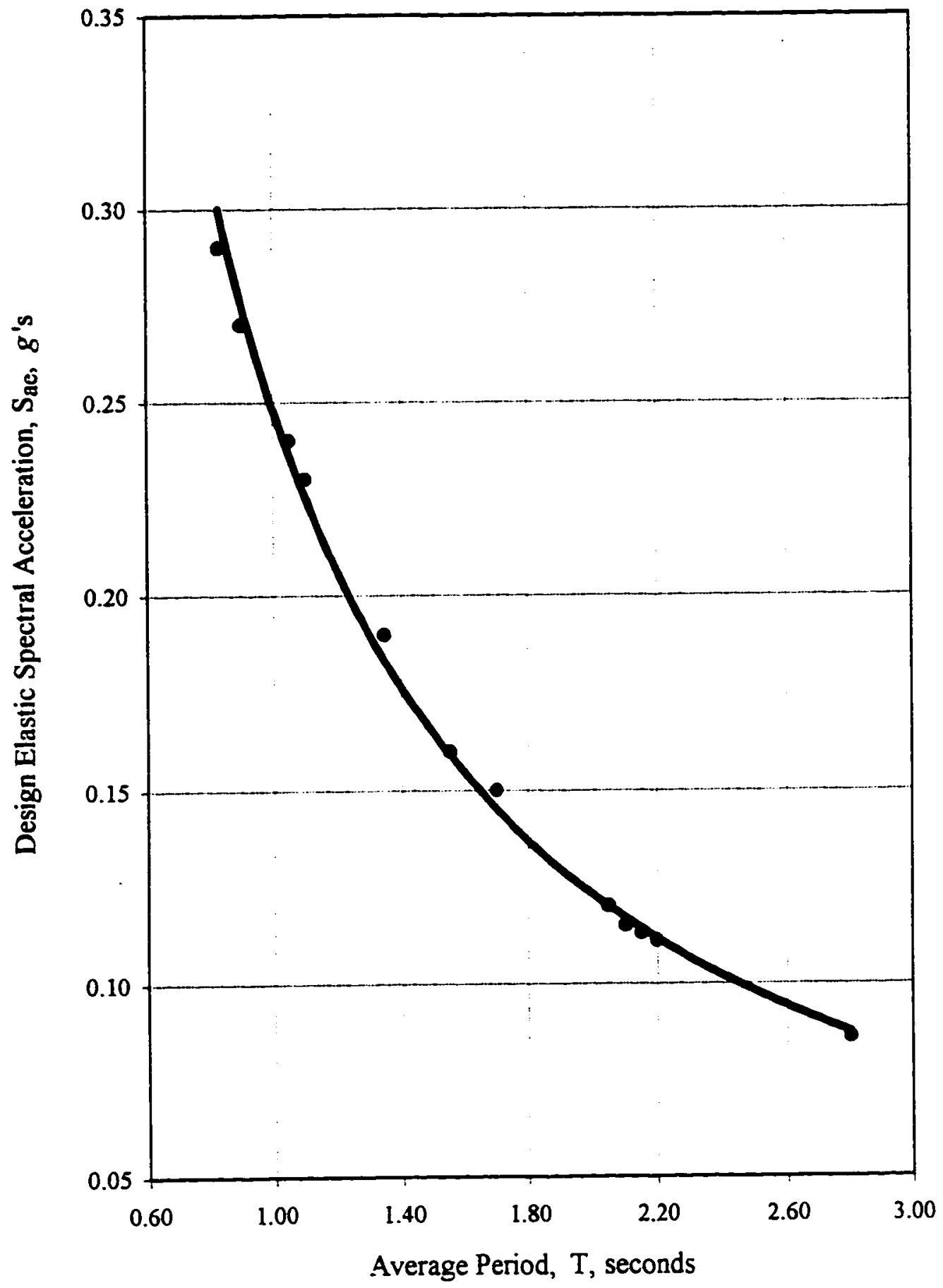


Figure 4-4

Structural System Factor, $\mathbf{R}_{\mathbf{w}}$, vs. Period, $\mathbf{T}$, for RCMRF

Structures with System Ductility Factors $\mu=1,2,3$, and 4

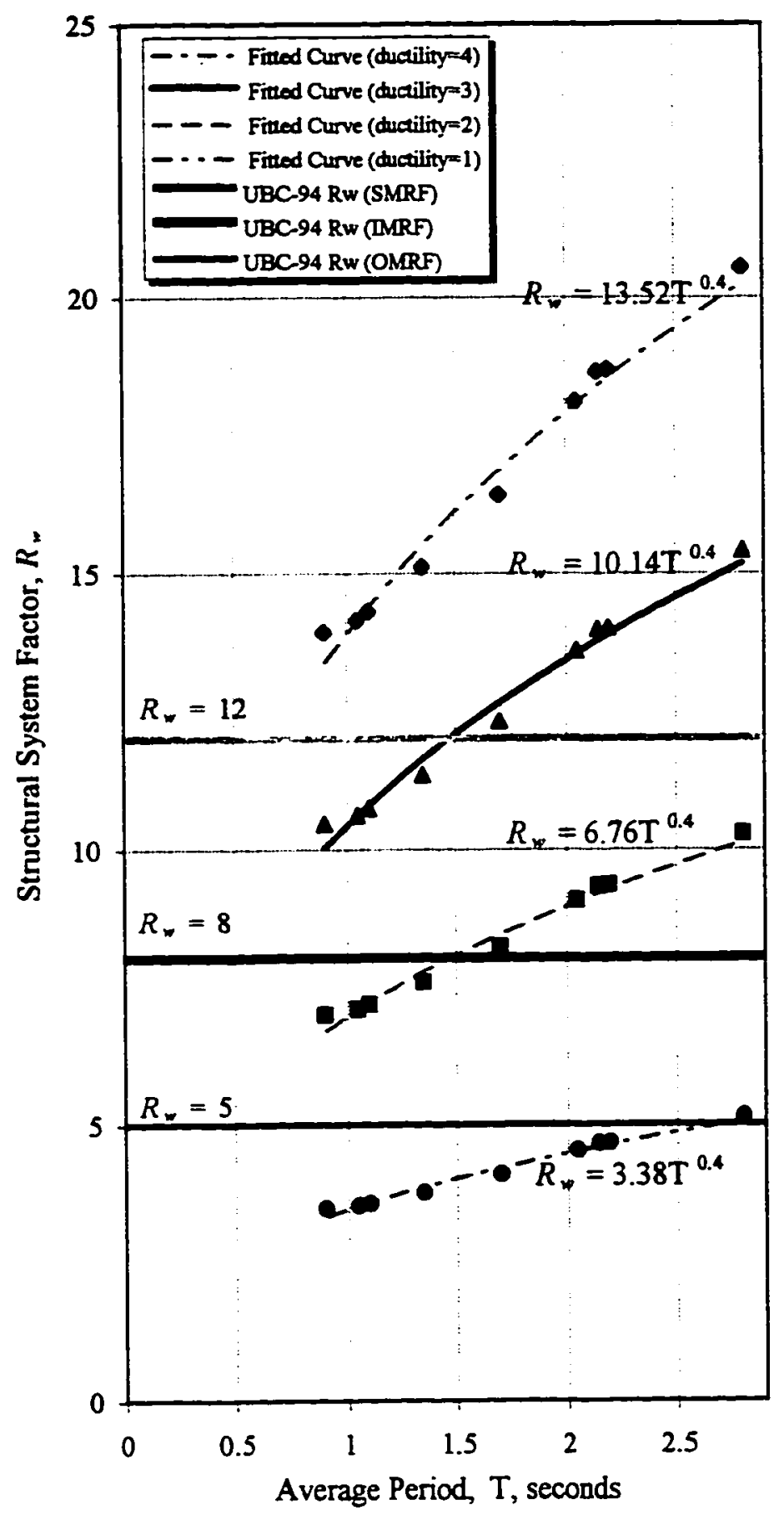




\section{Chapter 5}

\section{EVALUATION OF UNCERTAINTY IN THE BASE SHEAR FORMULA}

\subsection{Backeround and Obiectives:}

The limitations of the UBC-94 base shear formula are discussed in Chapter 2. As mentioned in previous chapters, all parameters of this formula, except the weight, the period, and the height of the structure, are given in appropriate tables listed in UBC-94. In the UBC-94 base shear Formula [28-1] (Formula [2-1] of this study), in addition to the shortcomings mentioned previously, no uncertainty is assigned to the building period, $\mathrm{T}$, or the structural system factor, $R_{w}$. It is, therefore, up to the designer to use his or her "engineering judgment" to account for any uncertainty that is associated with this formula.

The reliability of the UBC-94 base shear formula, particularly in the presence of empirical factors such as structural system factor, $R_{w}$, is highly questionable, and much further research is necessary to fully justify this formula. The application of Formula [28-1] to make initial estimations of member sizes in a dynamic analysis approach may not be as critical as in the static equivalent approach. Since a dynamic analysis is usually performed on a computer, the main disadvantage of an inaccurate initial sizing estimation formula would be the computational expense. However, the use of this formula with its empirical parameters as a primary formula in the equivalent static load approach, without 
considering any band of variation in its parameters, could possibly invalidate the concept of a safe design.

The main objective of this chapter is to study the uncertainty in the UBC-94 base shear Formula [28-1] by utilizing the simulation-based computer program $M$-Star. In previous chapters, the procedures for developing frequency distributions for the fundamental period and structural system factor of the UBC-94 base shear formula were discussed. In this chapter, these procedures are used to develop the frequency distributions in the form of bounded frequency histograms for these parameters considering some level of uncertainty.

\subsection{Method of Analysis of Two or More Variables:}

To explain the logic behind utilization of $M$-Star for analyzing two or more variables, a brief discussion is presented here before developing the appropriate histograms to use as M-Star input.

Any formula that is used to describe a model or a system may contain some variables with certain levels of uncertainty associated with them. If it is desirable to consider the level of uncertainty in a formula, such as Formula [28-1] of the UBC-94, this formula can be studied using a probabilistic approach. As mentioned in Chapter 1, while a probabilistic approach seems to be appropriate for evaluation of uncertainty in Formula [28-1] of the 
UBC-94, probabilistic distributions of the two main parameters of this formula, $\mathrm{T}$ and $R_{w}$, are difficult to combine mathematically using closed-form solutions. The M-Star computer program is used mainly as a tool to combine the distributions of $\mathrm{T}$ and $R_{\mathrm{w}}$ probabilistically.

M-Star is a simulation-based computer program used for the probabilistic evaluation of formulas with one or more random variables. M-Star allows the simultaneous interaction of different parameters of any formula when these parameters are represented by their distributions. It can provide solution of formulas containing up to 30 random variables, where each variable may be expressed by its bounded histogram [33]. A complete list of valid symbols and the instructions on how to run M-Star can $\mathrm{n}$ be found in Appendix $\mathrm{A}$ and References [31], [32] and [33].

It is crucial to mention that the reliability of the results obtained from $M$-Star mainly depends on the ability of each histogram to accurately represent each variable. Therefore, it is essential to develop realistic distributions for each variable of the investigated formula to achieve the most accurate and the most unbiased results.

\subsection{Parametric Assumptions:}

To evaluate uncertainty in the base shear Formula [28-1] of the UBC-94 (Formula [2-3] of 
this study) using M-Star, this formula is rearranged as (see Section 2.3 for definition of parameters):

$$
\frac{V}{W}=\frac{Z I C}{R_{w}}
$$

where $\mathrm{C}$ is:

$$
C=\frac{1.25 S}{T^{23}} \leq 2.75
$$

The ratio of $\mathrm{V} / \mathrm{W}$ is the targeted value to be analyzed using M-Star, considering uncertainty in the parameters $R_{w}$ and T. Also called here the base shear coefficient (BSC), V/W represents the ratio of the total design base shear (or lateral force) of the structure, $\mathrm{V}$, to the total seismic dead load of the structure, $\mathrm{W}$. This ratio of $\mathrm{V} / \mathrm{W}$ is of significant importance because it provides the designer with a simple measure of the total base shear as a percentage of the total seismic dead load of the structure. Therefore, $\mathrm{V}$ can be studied as a percentage of $\mathrm{W}$ without assigning any level of uncertainty to $\mathrm{W}$.

Other parameters of Formula [5-1] are assumed to have the following values:

$$
\begin{array}{ll}
Z=0.4 & \text { Seismic zone } 4 \text { (Table 16-I) } \\
S=1.0 & \text { Soil type } S_{1} \text { (Table 16-J) } \\
I=1.0 & \text { Standard occupancy structure (Table 16-K) }
\end{array}
$$


For the scope of this study, no uncertainty is assigned to these parameters. A value of 0.4 is assumed to be appropriate for $Z$ since all of the buildings of the database of this study are located in parts of California corresponding to seismic zone 4 (see Figure 16-2, UBC94). In addition, to be consistent with the design spectrum for MPE used in Section 4.5.2 (Figure 4-2), the soil profile $S_{1}$ is assumed to describe the soil characteristics of the sites where the buildings of this study are located $(S=1.0)$. The seismic importance factor, $I$, is also assumed to have a value of one for the buildings of this study since these buildings are standard occupancy structures.

While there is no value or uncertainty assigned to $\mathrm{W}$, for calculating the design base shear, W must be estimated using the weight of the individual components of the structural system. It is well recognized among the designers that although there are some uncertainties in estimating the total seismic dead load of the structure for seismic design, these uncertainties are significantly smaller than those involved in the estimation of the building period, $\mathrm{T}$, and structural system factor, $R_{w}$, particularly at the preliminary stage of the design. This is true since, as defined in UBC, the total seismic dead load of the structure is the total dead load from the weight of the structural and non-structural components of the structure and can be estimated with reasonable accuracy. However, the uncertainty involved in calculating the total seismic dead load of a structure is substantially increased when $25 \%$ of the floor live load is added to the total seismic dead load for the warehouse occupancy structures. This is because of the uncertainty involved 
in predicting the maximum value of the live load that could occur during the life time of the structure. Since none of the buildings of this study is a warehouse occupancy structure, the uncertainty involved in calculating $W$ is assumed to be negligible.

\subsection{Developing the Historrams 1 :}

To prescribe some levels of uncertainty in $T$ and $R_{w}$, these parameters must be represented by their appropriate probability density functions. In Sections 3.7 and 4.5 procedures for developing the distributions for these parameters were discussed in detail. In this section, the histograms for these distributions are developed to be used as input files for $M$-Star.

\subsubsection{Histograms of Building Period. T:}

Table 3-3 summarizes the average of the measured periods in both directions and the upper and lower limits of the $95 \%$ confidence intervals that were estimated. A truncated normal distribution, with a mean corresponding to the period value calculated from the regression analysis and upper and lower bounds corresponding to the $95 \%$ confidence intervals, is developed for each building of Table 3-3. As shown in the sample histogram of Figure 5-1 for Building 8 (see Table 3-3), the normal distribution for $T$ consists of a

\footnotetext{
${ }^{1}$ Bounded histograms are used in this study since $M$-Star is designed to use bounded frequency
} histograms as its input files. 
minimum value equal to the $95 \%$ lower confidence limit of 0.49 seconds and a maximum value equal to the $95 \%$ upper confidence limits of 1.78 seconds. In this study a total of 14 bounded histograms, one for each building, were developed. These histograms are used to represent the distributions of random variable $\mathrm{T}$ when applying $M-$ Star.

\subsubsection{Histogram of Structural System Factor, $R_{w}$ :}

As described in Section 4.5, four formulas were developed relating $R_{w}$ to period $\mathrm{T}$ corresponding to four system ductilities of $\mu=1,2,3$, and 4 (see Chapter 4 for the definition of system ductility). These formulas are presented in Figure 4-4, and they can be written in a general form of:

$$
R_{w}=n T^{04}
$$

where $n=3.38,6.76,10.14$, and 13.52 corresponds to system ductility factors of $1,2,3$, and 4, respectively. Each of these formulas representing $R_{w}$ contains $\mathrm{T}$ as its only variable; therefore, each distribution of $\mathrm{T}$ developed in Section 5.4.1 results in a distribution for $R_{w}$. Furthermore, to include some uncertainty in the $R_{w}$ distributions corresponding to the uncertainty associated with the system ductility, each distribution of $R_{w}$ is multiplied by a uniform distribution. This uniform distribution is called $R_{v a n}$ and it has a minimum value of 0.9 and a maximum value of 1.1 , allowing each $R_{\mathrm{w}}$ distribution to 
vary by $\pm 10 \%, R_{v a r}$ is presented in Figure $5-2$. The $R_{w}$ histograms developed from the above procedure are used to represent the frequency distribution curves of variable $R_{w}$ when applying M-Star.

\subsection{Uncertainty Evaluation Using M-Star:}

A total of 56 trials were conducted in this study. These trials correspond to four formulas (Formula [4-11] with four different values of $n$ corresponding to different system ductility factors given in Section 5.4.2) and one histogram for $R_{w}$, and 14 histograms for $\mathrm{T}$ (see Sections 5.4.1 and 5.4.2 for histograms).

For each structure of this study, four levels of system ductility of $1,2,3$, and 4 were considered where each level of ductility was used in the calculation of $R_{w}$ using Formula [5-2]. The resulting BSC (V/W ratio) from M-Star for each case is then compared with the V/W ratio calculated from Formula [28-1] of UBC-94.

It must be mentioned that although values of $R_{w}=5,8$, and 12 are given in Table $16-\mathrm{N}$ of UBC-94 for different types of concrete moment resisting frames to be used in Formula [28-1], Footnotes 5 and 7 of this table do not allow the use of $R_{w}=5$ and 8 in seismic zones 3 and 4. To be consistent with this UBC approach, since all of the buildings of the database of this study are located in seismic zone 4 , the value of $R_{w}=12$ is used for all of 
the buildings of this study when calculating the BSC using Formula [28-1] of UBC. Furthermore, in each trial, the bounds of the resulting distributions and different probabilities of non-exceedance for these distributions are considered, and the results are summarized accordingly. To be consistent with the UBC-94 limitation on C (see Formula [2-2]), the value of $C$ is also examined in each trial to ensure that it does not exceed the limiting value of 2.75 .

Figure 5-3 serves as an example of the resulting histogram of BSC for Building 8 (with a height of 78 feet). As shown in this figure, the histogram has a maximum BSC value of approximately 0.35 . This indicates that for Building 8 , with its particular period, height, and assumed system ductility, it is extremely unlikely that the design base shear, V, will exceed $35 \%$ of the seismic dead load of the structure, W. Also shown in Figure 5-3 are the values of the $99,99.9$, and 99.99 percentiles of the frequency distribution for BSC.

A detailed analysis and a comparison of the M-Star resulting distributions with the calculated values of BSC using the UBC-94 base shear formula are presented in the next section.

\subsection{Analysis and Discussion of Results and Comparison with UBC:}

Tables 5-1 to 5-4 and Figures 5-4 to 5-8 summarize the results of this study. For 
comparison, the values of the BSC from Formula [28-1] are also calculated for the database of this study (Table 3-3). The values of the base shear coefficient are plotted in these figures for the buildings of the database against their heights assuming system ductility factors ranging from 1 to 4 .

Figure 5-4 is a comparison between the lower bounds of the BSC distributions from $M$ Star and the BSC calculated using the UBC-94 formula. The lower bounds of the distributions from M-Star correspond to the combination of the minimum values of the distributions of $\mathrm{T}$ and $R_{w}$ considering other assumptions described previously in Section 5.3. For the buildings with an assumed system ductility of one, the lower bounds of the resulting distribution for the BSC are much higher than the values of BSC calculated using the UBC formula. As the system ductility increases, the lower bounds of the resulting BSC distributions fall below the BSC curve calculated using the UBC formula.

A comparison of the median values of the BSC distributions with the UBC-94 is shown in Figure 5-5. As shown in this figure, the median values of the BSC distributions for structures with system ductility factor of 2 and height of 220 feet and above, correlate well with the calculated values of BSC from UBC. As shown in Figure 5-5, it appears that for the buildings with the system ductility factors of 3 and 4 , the UBC values of the BSC are conservative. However, for the buildings with the assumed system ductility factors of 1 and 2, the values of BSC from the UBC formula represent unconservative values. This is 
significant for buildings with shorter periods since, as mentioned in Section 4.6 , buildings with short periods are usually low to medium rise structures and they require higher ductility demands. Therefore, it could be concluded that the calculated values of BSC from UBC-94 may represent conservative values for medium rise RCMRF structures with short periods and with system ductility factors of 3 and higher.

As was also discussed in Sections 4.4 and 4.6, defining a low system ductility factor of one or less implies that the structure will remain elastic during the earthquake excitation. Thus, from Figure 5-5 it may also be concluded that the current values of BSC from UBC formula do not represents a conservative value for an elastic design with an assumed system ductility of one. However, in practice, to benefit from the inelastic energy absorption capacity of structures, it is more feasible to design ductile RCMRF structures (with system ductility factors of greater than one) to behave inelastically during strong earthquakes while maintaining their integrity.

Figure 5-8 shows the upper bounds of the distributions resulting from M-Star. These maximum values correspond to the simultaneous combination of the upper bound values of the distributions of $\mathrm{T}$ and $R_{w}$ considering the assumptions mentioned previously in Section 5.3. These upper bound values of the BSC are also compared with the base shear coefficients calculated using the UBC formula. For all values of the assumed system ductility factor $(\mu)$, the resulting BSC from M-Star are higher than the calculated BSC 
values from the UBC-94. It is evident that the resulting values of $\mathrm{BSC}$ converge as the buildings become taller and as the assumed levels of system ductility increase. For the buildings of the database with the assumed system ductility factors of 3 and heights above $175 \mathrm{ft}$, and assumed system ductility factor of 4 and heights above $130 \mathrm{ft}$, the upper bounds of the BSC distributions resulting from M-Star closely capture the BSC values of UBC.

Similar trends are found in Figures 5-6 and 5-7. These figures suggest that for an assumed system ductility of 3 and for buildings with heights above 130 feet, the 99 and 99.5 percentile values of the BSC distributions correlate well with the values of BSC from UBC. Likewise, for the assumed system ductility of 4 , the 99 and 99.5 percentile values of the resulting BSC are identical to the calculated values from UBC for buildings with a height of approximately 120 feet. Similar to Figure 5-8, evidently, the distributions of the BSC's of these figures converge as the height of structures increases, particularly for system ductility of 3 and for 99 to and 99.5 percentiles.

It should be mentioned that Figure $5-4$ is presented in this study for comparison only, and the results obtained from this figure have no practical application for design purposes. This is because the resulting BSC values from Figure $5-4$ are lower bounds, and these BSC values have an extremely low probability of occurrence. However, the median values of the resulting BSC distributions obtained from Figures 5-5 may be used for the 
base shear design of RCMRF structures considering the design philosophy and the weight of the structures. These BSC values may be used for design purposes considering the appropriate load factors (for example, load factors of 1.4 and or 1.43 from ACI strength design method, See Reference [2], Page 318/318R/89). Likewise, the maximum values of the resulting BSC distributions presented in Figure 5-8 may be used for the base shear design of RCMRF structures. These maximum BSC values may be considered as factored loads since they are the upper bounds of the BSC distributions. 
Table 5-1

Results of Uncertainty Evaluation of UBC-94 Base Shear Formula 28-1 for Buidings with System Ductility $=1(\mu=1)$

\begin{tabular}{|c|c|c|c|c|c|c|c|c|}
\hline \multirow{3}{*}{$\begin{array}{l}\text { Bldg. } \\
\text { No. }\end{array}$} & \multirow{3}{*}{$\begin{array}{c}\text { Building } \\
\text { Height } \\
\text { (feet) }\end{array}$} & \multirow{3}{*}{$\begin{array}{l}\text { Average of } \\
\text { Measured } \\
\text { Periods, T } \\
\text { (seconds) }\end{array}$} & \multirow{3}{*}{$\begin{array}{c}\text { Calculated } \\
\text { Values of } \\
\text { V/ W Using } \\
\text { UBC Formula }\end{array}$} & \multicolumn{5}{|c|}{ Resulting V/W Distributions } \\
\hline & & & & \multicolumn{3}{|c|}{$\begin{array}{c}\text { Distribution } \\
\text { Characteristics }\end{array}$} & \multicolumn{2}{|c|}{$\begin{array}{c}\text { Selected } \\
\text { Percentiles }\end{array}$} \\
\hline & & & & Min. & Median & Max. & 99 & 99.5 \\
\hline 1 & 205 & 2.05 & 0.03 & 0.04 & 0.07 & 0.11 & 0.09 & 0.09 \\
\hline 4 & 184 & 2.2 & 0.03 & 0.05 & 0.07 & 0.12 & 0.10 & 0.10 \\
\hline 5 & 66 & 1.05 & 0.05 & 0.08 & 0.14 & 0.48 & 0.29 & 0.32 \\
\hline 6 & 119 & 1.35 & 0.04 & 0.06 & 0.10 & 0.19 & 0.15 & 0.15 \\
\hline 8 & 78 & 1.1 & 0.05 & 0.07 & 0.13 & 0.35 & 0.24 & 0.26 \\
\hline 9 & 300 & 2.8 & 0.02 & 0.03 & 0.05 & 0.08 & 0.07 & 0.07 \\
\hline 10 & 48 & 0.9 & 0.06 & 0.08 & 0.17 & 1.09 & 0.47 & 0.56 \\
\hline 11 & 124 & 1.35 & 0.04 & 0.06 & 0.09 & 0.18 & 0.13 & 0.14 \\
\hline 13 & 160 & 1.7 & 0.04 & 0.05 & 0.08 & 0.14 & 0.11 & 0.12 \\
\hline 14 & 166 & 2.15 & 0.03 & 0.05 & 0.08 & 0.13 & 0.11 & 0.11 \\
\hline 15 & 120 & 1.35 & 0.04 & 0.06 & 0.10 & 0.19 & 0.15 & 0.15 \\
\hline 16 & 149 & 1.55 & 0.04 & 0.06 & 0.08 & 0.15 & 0.12 & 0.12 \\
\hline 17 & 188 & 2.1 & 0.03 & 0.05 & 0.07 & 0.12 & 0.10 & 0.10 \\
\hline 18 & 65 & 0.83 & 0.05 & 0.08 & 0.14 & 0.50 & 0.31 & 0.34 \\
\hline
\end{tabular}

${ }^{1}$ From Bendimerad, Shah, and Hoskins (Reference [7]) with permission. 
Table 5-2

Results of Uncertainty Evaluation of UBC-94 Base Shear Formula 28-1 for Buildings with System Ductility $=2(\mu=2)$

\begin{tabular}{|c|c|c|c|c|c|c|c|c|}
\hline Bidg. & Building & Average of & Calculated & \multicolumn{4}{|c|}{ Resulting V/W Distributions } \\
\cline { 5 - 9 } No. & $\begin{array}{c}\text { Height } \\
\text { (feet) }\end{array}$ & $\begin{array}{c}\text { Measured } \\
\text { Periods, } \mathrm{T}^{1}\end{array}$ & $\begin{array}{c}\text { Values of } \\
\text { V/ W Using }\end{array}$ & \multicolumn{3}{|c|}{$\begin{array}{c}\text { Distribution } \\
\text { Characteristics }\end{array}$} & \multicolumn{2}{c|}{$\begin{array}{c}\text { Selected } \\
\text { Percentiles }\end{array}$} \\
\cline { 6 - 10 } & & (seconds) & UBC Formula & Min. & Median & Max. & 99 & 99.5 \\
\hline 1 & 205 & 2.05 & 0.03 & 0.02 & 0.03 & 0.06 & 0.05 & 0.05 \\
\hline 4 & 184 & 2.2 & 0.03 & 0.02 & 0.04 & 0.06 & 0.05 & 0.05 \\
\hline 5 & 66 & 1.05 & 0.05 & 0.04 & 0.07 & 0.24 & 0.15 & 0.16 \\
\hline 6 & 119 & 1.35 & 0.04 & 0.03 & 0.05 & 0.09 & 0.07 & 0.08 \\
\hline 8 & 78 & 1.1 & 0.05 & 0.04 & 0.07 & 0.18 & 0.12 & 0.13 \\
\hline 9 & 300 & 2.8 & 0.02 & 0.02 & 0.02 & 0.04 & 0.03 & 0.04 \\
\hline 10 & 48 & 0.9 & 0.06 & 0.04 & 0.08 & 0.54 & 0.23 & 0.28 \\
\hline 11 & 124 & 1.35 & 0.04 & 0.03 & 0.05 & 0.09 & 0.07 & 0.07 \\
\hline 13 & 160 & 1.7 & 0.04 & 0.03 & 0.04 & 0.07 & 0.06 & 0.06 \\
\hline 14 & 166 & 2.15 & 0.03 & 0.03 & 0.04 & 0.07 & 0.05 & 0.06 \\
\hline 15 & 120 & 1.35 & 0.04 & 0.03 & 0.05 & 0.09 & 0.07 & 0.08 \\
\hline 16 & 149 & 1.55 & 0.04 & 0.03 & 0.04 & 0.07 & 0.06 & 0.06 \\
\hline 17 & 188 & 2.1 & 0.03 & 0.02 & 0.04 & 0.06 & 0.05 & 0.05 \\
\hline 18 & 65 & 0.83 & 0.05 & 0.04 & 0.07 & 0.25 & 0.15 & 0.17 \\
\hline
\end{tabular}

${ }^{1}$ From Bendimerad, Shah, and Hoskins (Reference [7]) with permission. 
Table 5-3

Results of Uncertainty Evaluation of UBC-94 Base Shear Formula 28-1 for Buildings with System Ductility $=3(\mu=3)$

\begin{tabular}{|c|c|c|c|c|c|c|c|c|}
\hline \multirow{3}{*}{$\begin{array}{l}\text { Bldg. } \\
\text { No. }\end{array}$} & \multirow{3}{*}{$\begin{array}{c}\text { Building } \\
\text { Height } \\
\text { (feet) }\end{array}$} & \multirow{3}{*}{$\begin{array}{l}\text { Average of } \\
\text { Measured } \\
\text { Periods, } T^{1} \\
\text { (seconds) }\end{array}$} & \multirow{3}{*}{$\begin{array}{l}\text { Calculated } \\
\text { Values of } \\
\text { V/ W Using } \\
\text { UBC Formula }\end{array}$} & \multicolumn{5}{|c|}{ Resulting V/W Distributions } \\
\hline & & & & \multicolumn{3}{|c|}{$\begin{array}{c}\text { Distribution } \\
\text { Characteristics }\end{array}$} & \multicolumn{2}{|c|}{$\begin{array}{c}\text { Selected } \\
\text { Percentiles }\end{array}$} \\
\hline & & & & Min. & Median & Max. & 99 & 99.5 \\
\hline 1 & 205 & 2.05 & 0.03 & 0.01 & 0.02 & 0.04 & 0.03 & 0.03 \\
\hline 4 & 184 & 2.2 & 0.03 & 0.02 & 0.02 & 0.04 & 0.03 & 0.03 \\
\hline$\overline{5}$ & $\overline{66}$ & 1.05 & 0.05 & 0.03 & 0.05 & 0.16 & 0.10 & 0.11 \\
\hline 6 & 119 & 1.35 & 0.04 & 0.02 & 0.03 & 0.06 & 0.05 & 0.05 \\
\hline 8 & 78 & 1.1 & 0.05 & 0.02 & 0.04 & 0.12 & 0.08 & 0.09 \\
\hline 9 & 300 & 2.8 & 0.02 & 0.01 & 0.02 & 0.03 & 0.02 & 0.02 \\
\hline 10 & 48 & 0.9 & 0.06 & 0.03 & 0.06 & 0.36 & 0.15 & 0.19 \\
\hline 11 & 124 & 1.35 & 0.04 & 0.02 & 0.03 & 0.06 & 0.04 & 0.05 \\
\hline 13 & 160 & 1.7 & 0.04 & 0.02 & 0.03 & 0.05 & 0.04 & 0.04 \\
\hline 14 & 166 & 2.15 & 0.03 & 0.02 & 0.03 & 0.04 & 0.04 & 0.04 \\
\hline 15 & 120 & 1.35 & 0.04 & 0.02 & 0.03 & 0.06 & 0.05 & 0.05 \\
\hline 16 & 149 & 1.55 & 0.04 & 0.02 & 0.03 & 0.05 & 0.04 & 0.04 \\
\hline 17 & 188 & 2.1 & 0.03 & 0.02 & 0.02 & 0.04 & 0.03 & 0.03 \\
\hline 18 & 65 & 0.83 & 0.05 & 0.03 & 0.05 & 0.17 & 0.10 & 0.11 \\
\hline
\end{tabular}

${ }^{1}$ From Bendimerad, Shah, and Hoskins (Reference [7]) with permission. 
Table 5-4

Results of Uncertainty Evaluation of UBC-94 Base Shear Formula 28-1 for Buildings with System Ductility $=4(\mu=4)$

\begin{tabular}{|c|c|c|c|c|c|c|c|c|}
\hline \multirow{3}{*}{$\begin{array}{l}\text { Bldg. } \\
\text { No. }\end{array}$} & \multirow{3}{*}{$\begin{array}{c}\text { Building } \\
\text { Height } \\
\text { (feet) }\end{array}$} & \multirow{3}{*}{$\begin{array}{l}\text { Average of } \\
\text { Measured } \\
\text { Periods, } \mathrm{T}^{1} \\
\text { (seconds) }\end{array}$} & \multirow{3}{*}{$\begin{array}{l}\text { Calculated } \\
\text { Values of } \\
\text { V/ W Using } \\
\text { UBC Formula }\end{array}$} & \multicolumn{5}{|c|}{ Resulting V/W Distributions } \\
\hline & & & & \multicolumn{3}{|c|}{$\begin{array}{l}\text { Distribution } \\
\text { Characteristics }\end{array}$} & \multicolumn{2}{|c|}{$\begin{array}{c}\text { Selected } \\
\text { Percentiles }\end{array}$} \\
\hline & & & & Min. & Median & $\operatorname{Max}$ & 99 & 99.5 \\
\hline 1 & 205 & 2.05 & 0.03 & 0.01 & 0.02 & 0.03 & 0.02 & 0.02 \\
\hline 4 & 184 & 2.2 & 0.03 & 0.01 & 0.02 & 0.03 & 0.03 & 0.03 \\
\hline 5 & 66 & 1.05 & 0.05 & 0.02 & 0.04 & 0.12 & 0.07 & 0.08 \\
\hline 6 & 119 & 1.35 & 0.04 & 0.02 & 0.03 & 0.05 & 0.04 & 0.04 \\
\hline 8 & 78 & 1.1 & 0.05 & 0.02 & 0.03 & 0.09 & 0.06 & 0.07 \\
\hline 9 & 300 & 2.8 & 0.02 & 0.01 & 0.01 & 0.02 & 0.02 & 0.02 \\
\hline 10 & 48 & 0.9 & 0.06 & 0.02 & 0.04 & 0.27 & 0.12 & 0.14 \\
\hline 11 & 124 & 1.35 & 0.04 & 0.01 & 0.02 & 0.04 & 0.03 & 0.03 \\
\hline 13 & 160 & 1.7 & 0.04 & 0.01 & 0.02 & 0.03 & 0.03 & 0.03 \\
\hline 14 & 166 & 2.15 & 0.03 & 0.01 & 0.02 & 0.03 & 0.03 & 0.03 \\
\hline 15 & 120 & 1.35 & 0.04 & 0.02 & 0.02 & 0.05 & 0.04 & 0.04 \\
\hline 16 & 149 & 1.55 & 0.04 & 0.01 & 0.02 & 0.04 & 0.03 & 0.03 \\
\hline 17 & 188 & 2.1 & 0.03 & 0.01 & 0.02 & 0.03 & 0.02 & 0.03 \\
\hline 18 & 65 & 0.83 & 0.05 & 0.02 & 0.04 & 0.27 & 0.07 & 0.08 \\
\hline
\end{tabular}

'From Bendimerad, Shah, and Hoskins (Reference [7]) with permission. 
Figure 5-1

A Truncated Normal Distribution for Average Period, T, for Building 8 of Table 3-3

(Lower bound $=0.49$ seconds, Mean $=1.1$ seconds, Upper bound $=1.78$ seconds)

(Obtained Using M-Star Program, [31] and [32])

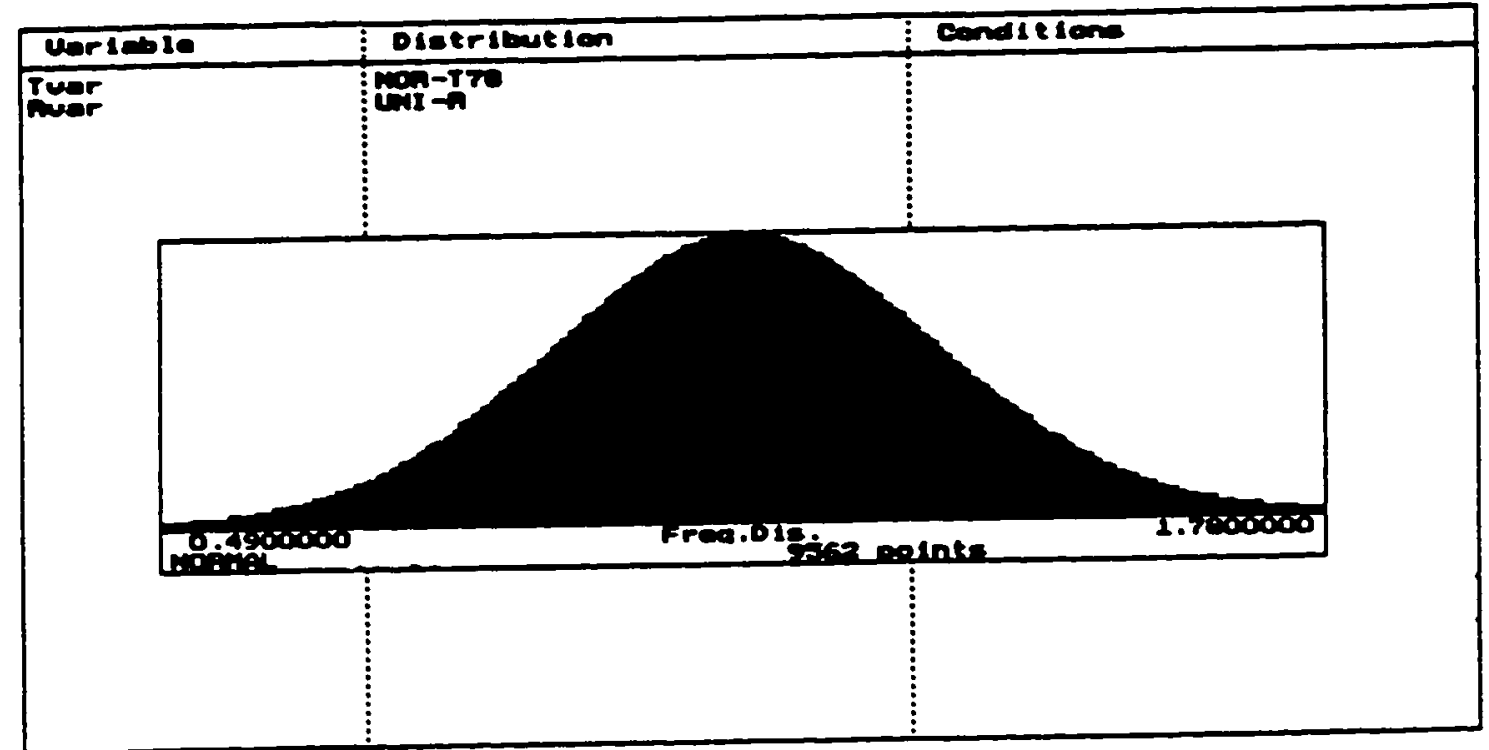


Figure 5-2

A Sample Uniform Distribution for $\mathbf{R}_{\mathbf{v a r}}$

(Obtained Using M-Star Program, [31] and [32])

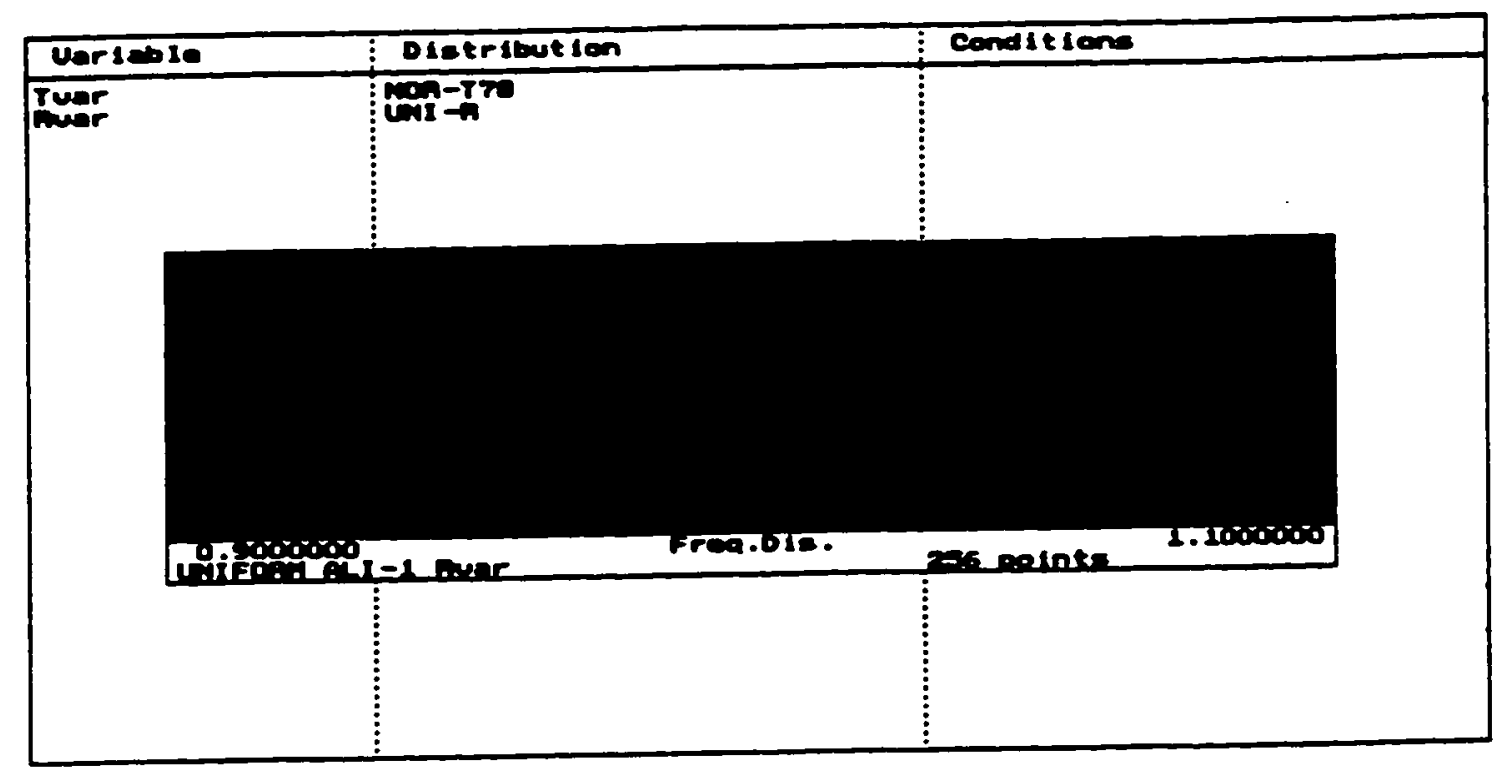


Figure 5-3

A Sample of the Resulting M-Star Frequency Distribution for Base Shear Coeficient, V/W, for Building 8 with System Ductility Factor $=1 \quad(\mu=1)$

(Obtained Using M-Star Program, [31] and [32])

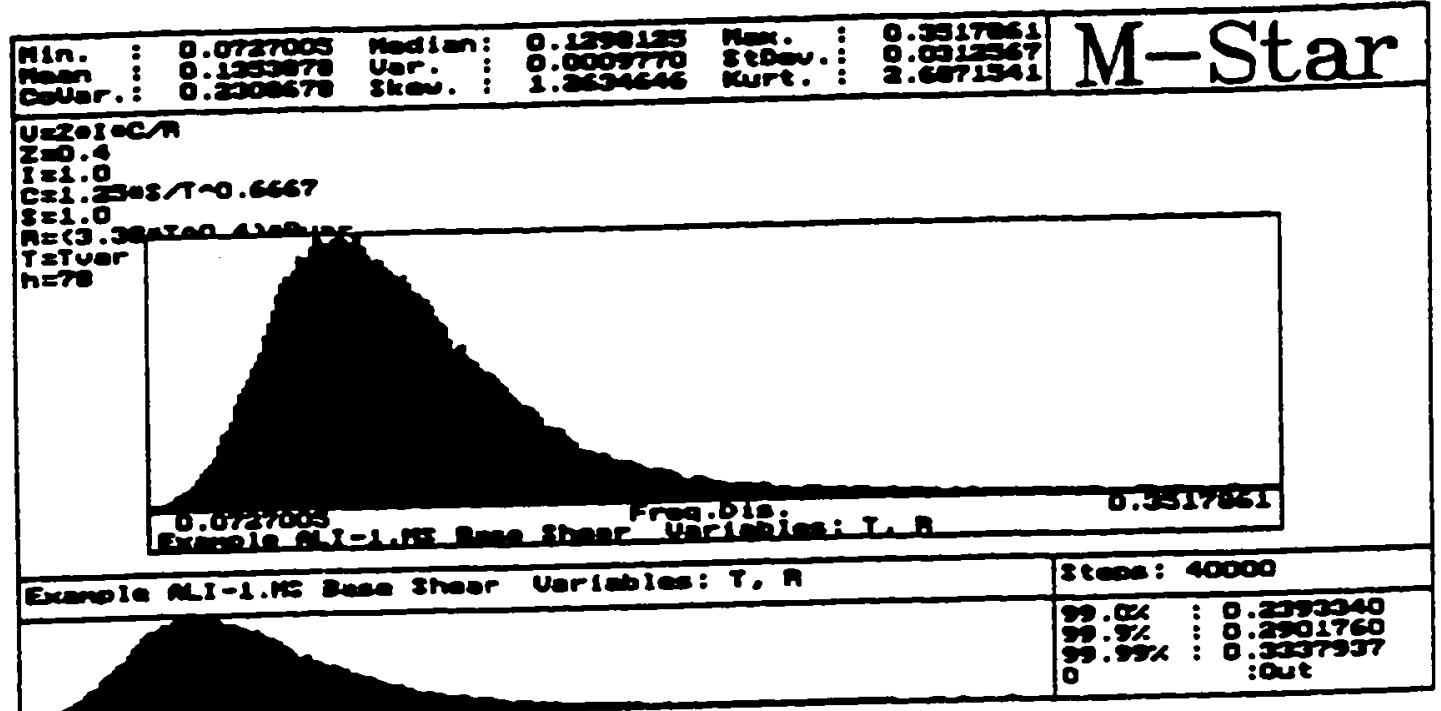




\section{Figure 5-4}

\section{Comparison of the Lower Bounds of the BSC Distributions with} UBC-94 Formula

$$
\begin{aligned}
& - \text { Lower Bounds of V/W from M-Star for Ductility }=1 \\
& - \text { Lower Bounds of V/W from M-Star for Ductility }=2 \\
& \text { Lower Bounds of V/W from M-Star for Ductility }=3 \\
& \text { - L - Lwer Bounds of V/W from M-Star for Ductility }=4 \\
& \text { Calculated Values of V/W Using UBC-94 Formula }
\end{aligned}
$$

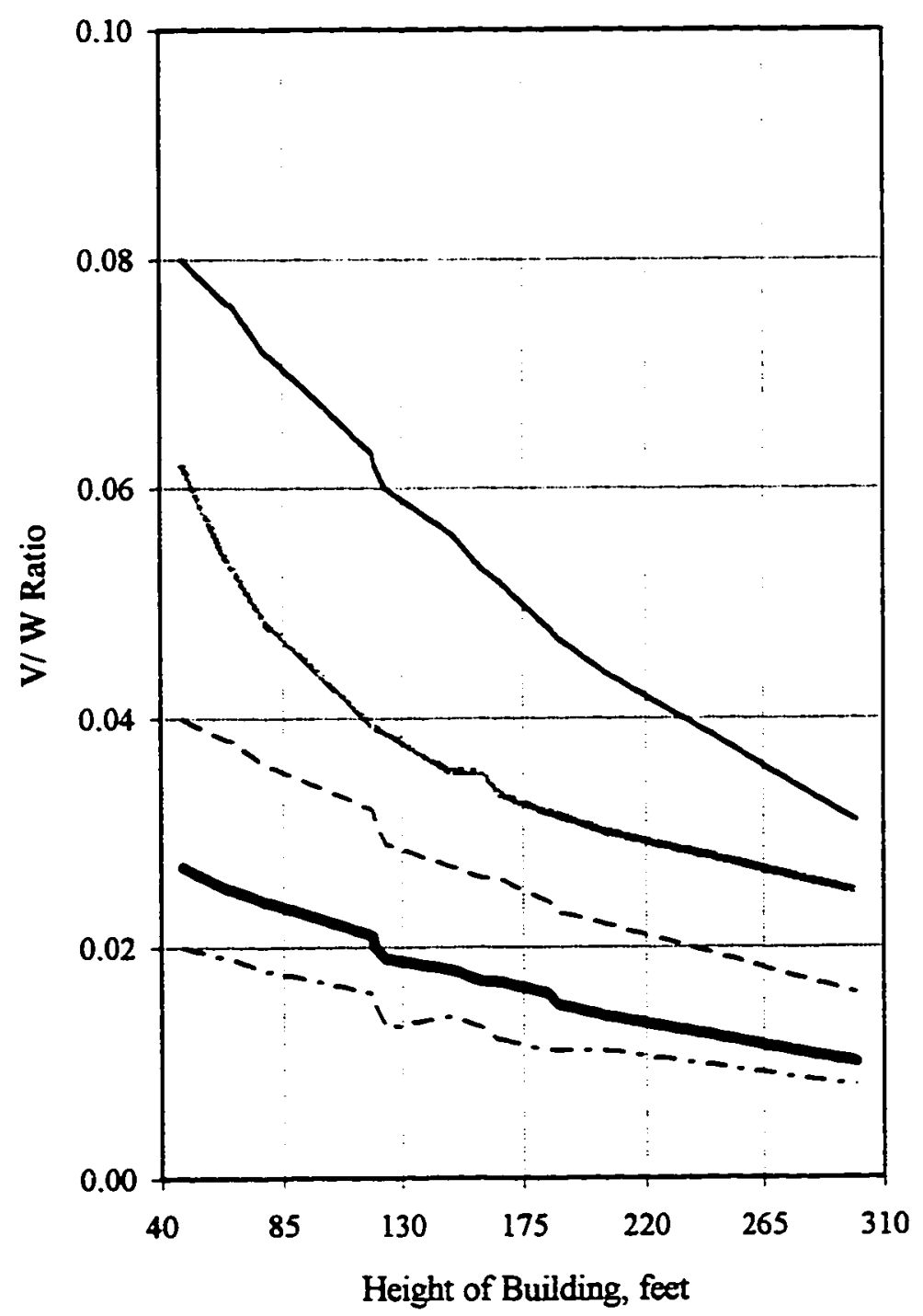




\section{Figure 5-5}

\section{Comparison of the Median Values of the BSC Distributions with}

UBC-94 Formula

Median Values of V/W from M-Star for Ductility = 1
- Median Values of V/W from M-Star for Ductility $=2$
- Median Values of V/W from M-Star for Ductility $=3$
- Median Values of V/W from M-Star for Ductility $=4$
Calculated Values of V/W Using UBC-94 Formula

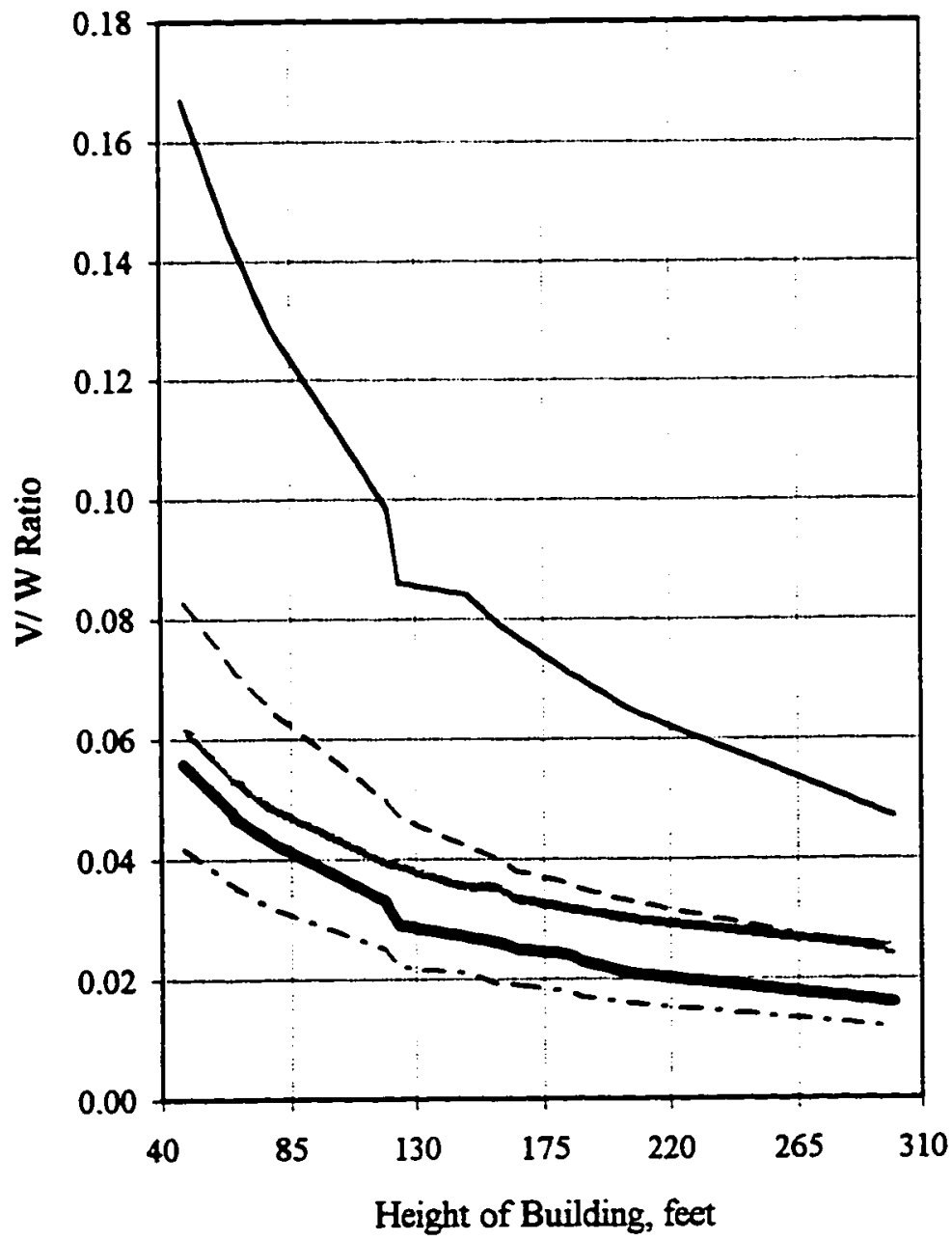


Figure 5-6

Comparison of the 99 Percentile Values of the BSC Distributions with UBC-94 Formula
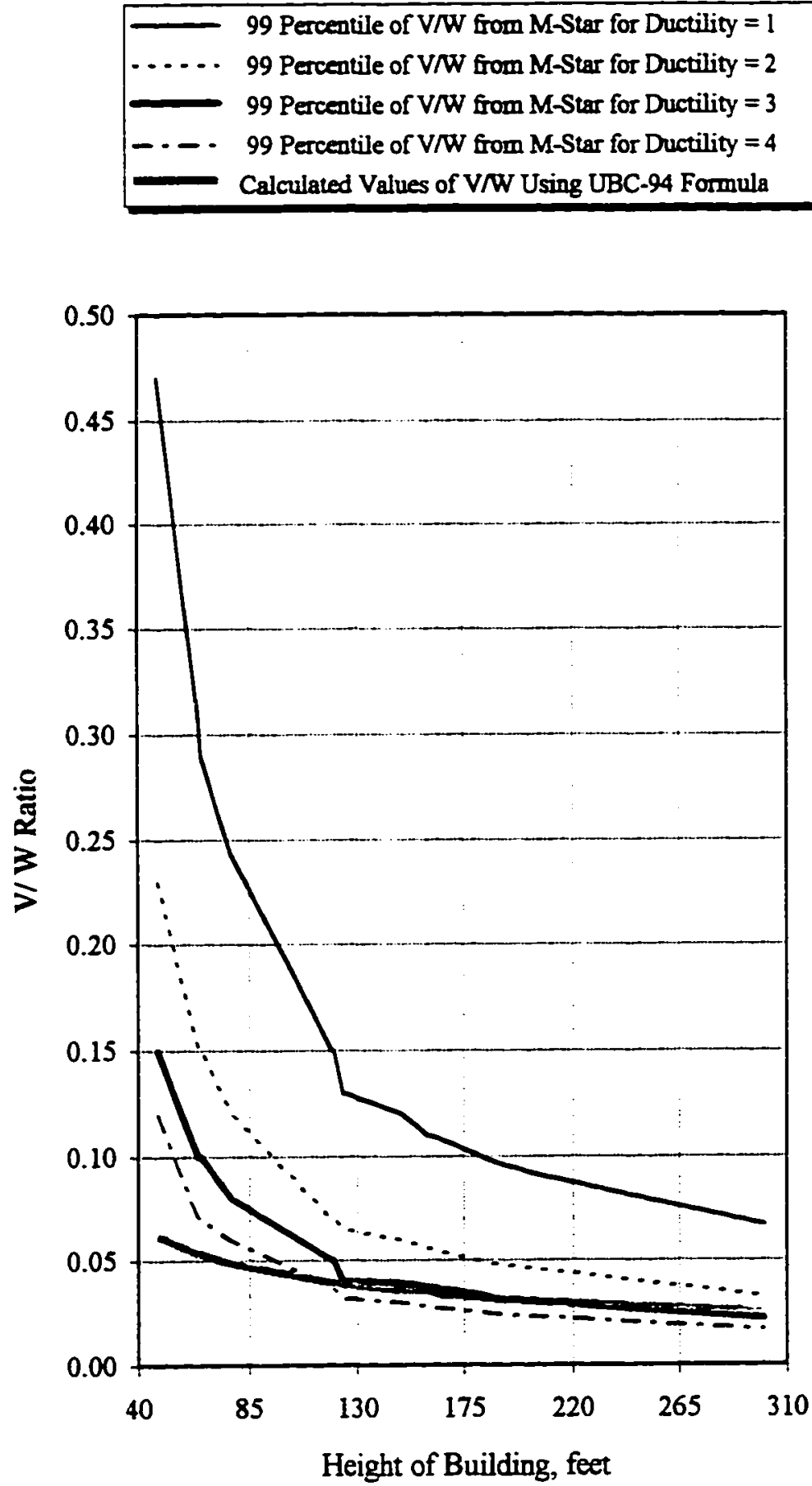
Figure 5-7

Comparison of the 99.5 Percentile Values of the BSC Distributions with UBC-94 Formula
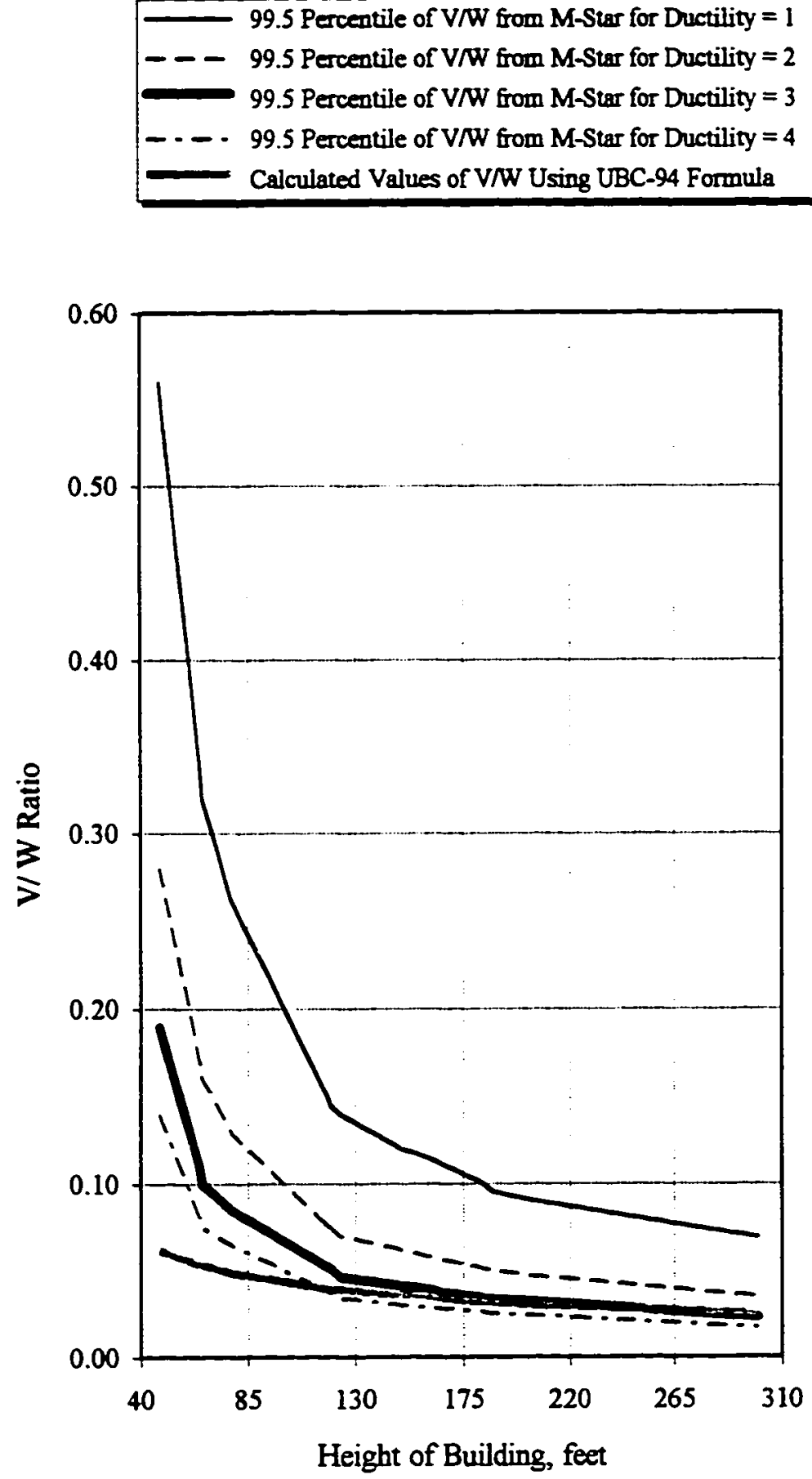


\section{Figure 5-8}

Comparison of the Upper Bounds of the BSC Distributions with UBC-94 Formula

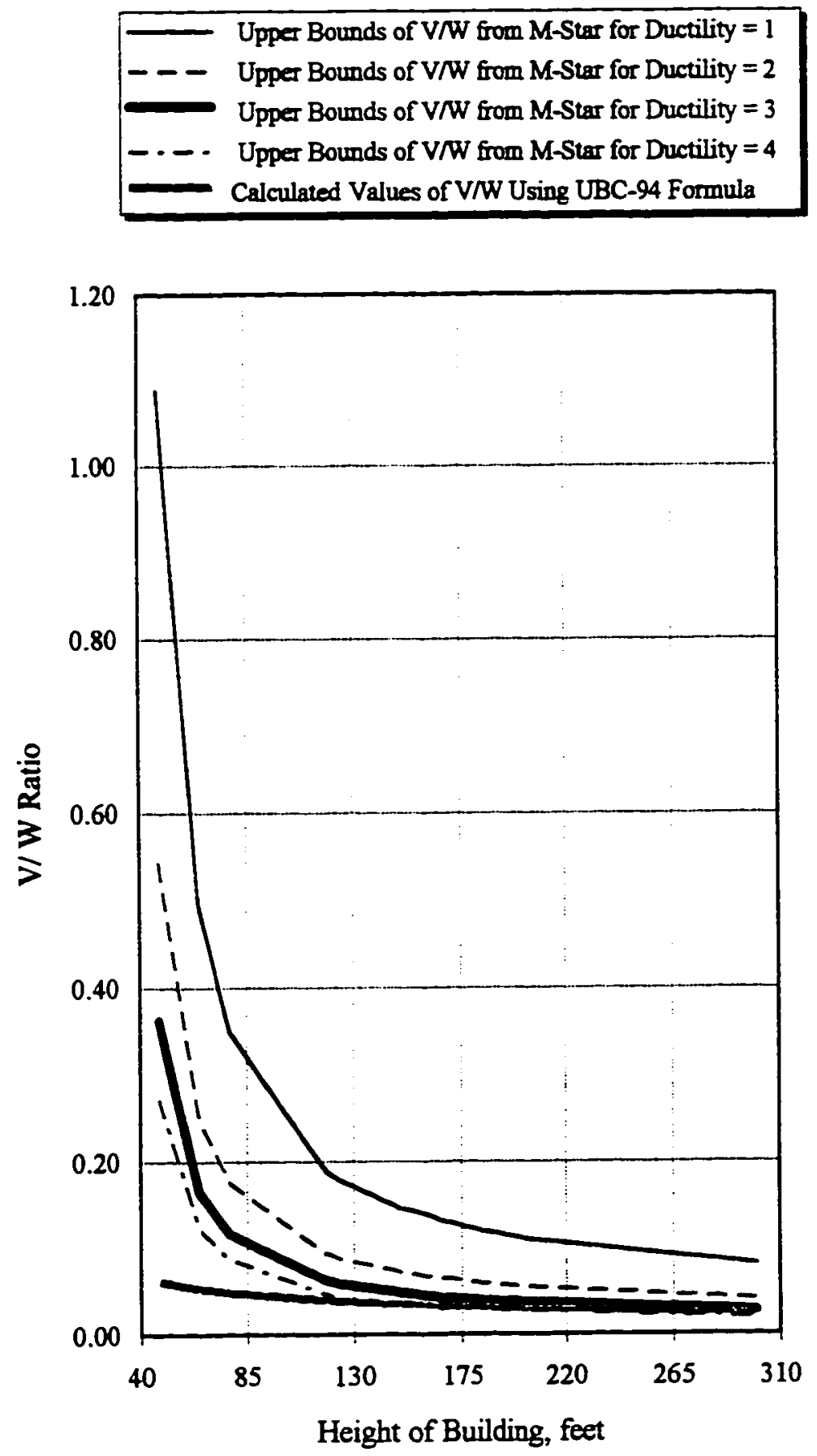




\section{Chapter 6}

\section{SUMMARY AND CONCLUSIONS}

\subsection{Summary of Study:}

This study represents an investigation of the UBC-94 equivalent static analysis approach in calculating the base shear forces for RCMRF structures. In this study, the UBC base shear formula, its rationale, and its shortcomings are discussed, and the parameters of this formula are explored. Furthermore, the influence of structural characteristics, structural properties, and ground motion characteristics on the response of RCMRF structures are discussed.

In order to understand the influence of uncertainty in parameters of the base shear Formula [28-1] of the Uniform Building Code 1994, this formula is investigated using an uncertainty evaluation technique, using the $M$-Star computer program. In this evaluation, some level of uncertainty is assigned to two main parameters of this formula, $\mathrm{T}$ and $R_{w}$. These levels of uncertainty are included in the analysis by means of appropriate probabilistic distributions for each parameter. Furthermore, using previous studies, a system ductility factor is included in the UBC formula to account for the ductility characteristics of the RCMRF structural systems of this study. The system ductility 
factors of $1,2,3$ and 4 are assigned to each structure regardless of the actual system ductility.

The database of this study consists of 14 RCMRF structures that performed adequately during the 1971 San Fernando, 1984 Morgan Hill, 1987 Whittier, and 1989 Loma Prieta earthquakes. The database used in this study is based on the database of Bendimerad et al. (Reference [7]).

\subsection{Conclusions:}

The results of this study have shown that the base shear formula (Formula [28-1]) of the $\mathrm{UBC}-94$ is sensitive to variations in the values of $\mathrm{T}$ and $R_{w}$. Based on the assumptions of previous studies and this study, it has been shown that the structural system factor, $R_{w}$, can be a function of the period of the structure, system ductility factor, and design acceleration response spectra, $S_{a e}$. It has also been shown that formulating the system ductility characteristics of the structural system is complicated and depends on several assumptions. The accuracy of these assumptions and the uncertainties involved in these assumptions are important factors in the overall variation of the base shear coefficients. More specifically, this study has shown that: 
1. As evidenced by the convergence of the curves in Figures 5-5 through 5-8 to a single curve, the effects of the uncertainty in $\mathrm{T}$ and $R_{\mathrm{w}}$ on the UBC-94 base shear force formula are minimized for RCMRF structures with a system ductility factor greater than 2 and height above 124 feet. Including uncertainty in these parameters has no significant effect on the UBC-94 base shear formula for RCMRF structures with heights above 220 feet and a system ductility factor of 2 .

2. It is apparent that for the buildings with system ductility factors of less than 2 , the values of the base shear coefficient (BSC), V/W, calculated from the UBC-94 formula are less than the median values of the BSC distributions which include period and structural system factor uncertainties. This suggests that the UBC-94 formula may be unconservative for buildings with low system ductility factors.

3. For buildings of the database of this study with the heights above 124 feet, the UBC-94 formula correlates well with the 99th percentile and higher values of base shear coefficient for system ductilities of 3 and 4 . This indicates that for higher system ductilities, the UBC-94 formula provides conservative design forces. 
4. Comparison of the median values of the BSC distributions with the UBC94 formula reveals that incorporating a system ductility factor into structural system factor, $R_{w}$, has significant effects on the resulting $\mathrm{BSC}$ distributions. While the design base shear forces are sensitive to system ductility, current UBC values of $R_{w}$ do not seem to represent conservative values for RCMRF structures of this study in seismic zone 4 and with low system ductility (less than 3 ).

5. The current UBC formula for initial estimation of the fundamental period (T) of RCMRF structures varies significantly from the estimated lower limit of the $95 \%$ confidence interval for the structures of this study. The results suggest that the lower limit of the $95 \%$ confidence interval is conservative in comparison with the current UBC formula since it represents lower period values, and therefore, higher base shear forces for RCMRF structures.

6. The reliability of the results of this study for RCMRF structures with heights below 78 feet may be lower than the reliability of the results for buildings above 119 feet in height. This is due to the paucity of buildings with heights below 78 feet in the refined database. 


\subsection{Recommendations:}

Uncertainty evaluation analysis is a useful approach for studying the effects of the design uncertainties in the UBC-94 equivalent static force procedure for earthquake lateral force design. The analysis of the results of this study compared favorably to the application of the UBC-94 base shear formula for medium-rise (heights of 130 to 300 feet) RCMRF structures with system ductility factor of 3 or greater. However, more research must be done for this approach to become available as an alternative method of analysis for structural designers.

1. The ability of the UBC-94 equivalent static force procedure to capture the effects of the system ductility of the RCMRF structures needs to be improved. Incorporating a system ductility factor based on the 1992 Englekirk study [13] seems to be an encouraging approach to capture these effects.

2. The use of uncertainty evaluation for structural systems other than reinforced concrete moment-resisting frame structures should be investigated using the appropriate database for these structures and appropriate period and ductility considerations. 
3. The uncertainty evaluation of the UBC-94 base shear formula could be expanded by assigning levels of uncertainties for other parameters such as the seismic zone factor, $\mathrm{Z}$, soil factor, $\mathrm{S}$, importance factor, $\mathrm{L}$, and the seismic dead load, W.

4. The current UBC criteria for selecting the structural system factor, $R_{w}$, needs to be justified further. In seismic zone 4 , the current value of $R_{w}$ does not appear to represent conservative values for RCMRF structures of this study with low system ductility (less than 3 ).

5. The period formula of the UBC-94 for initial estimation of the fundamental period, T, of RCMRF structures can be improved by including more structures of this type in the database as more data becomes available. This is of particular importance for improving the period estimation of short structures with heights below 78 feet since the current database does not include sufficient data for this type of buildings.

6. The probability of failure of the structures due to the earthquake loads can not be predicted, using the uncertainty evaluation technique, without establishing the resistance distributions for different structural elements. 
Efforts should be made to develop such resistance distributions for different structural elements accordingly.

This study represents an initial step in evaluating the uncertainties in different parameters of the UBC-94 static force procedure for RCMRF structures. The procedure is encouraging and may be used as a tool for optimizing the UBC-94 base shear Formula [28-1] to a more realistic formula that includes uncertainty in its parameters. However, a database consisting of more buildings will yield more justifiable results. Optimizing the formulation of the approximate static force procedure in this way may eventually lead to a more pragmatic procedure that is consistent with the uncertainties and complexities involved in earthquake design. 


\section{REFERENCES}

[1] American Concrete Institute, PCI Publication SP-53, Detroit, 1977.

[2] American Concrete Institute, "Building Code Requirements for Reinforced Concrete," ACI Publication ACI 318-89 and ACI 318R-89, Detroit, 1992.

[3] Applied Technology Council, "Tentative Provisions for the Development of Seismic Regulations for Buildings," ATC 3-06, 2nd Printing, Palo Alto, 1982.

[4] Austin, M. A., Pister, K. S. "Design of Seismic-Resistant Friction-Braced Frames," Journal of Structural Division, ASCE, Vol. 111, No. 12, 1985, pp. 2751-2769.

[5] Austin, M. A., Pister, K. S., and Mahin, S. A., "Probabilistic Design of EarthquakeResistant Structures," Journal of Structural Engineering, ASCE, Vol. 113, No. 8, 1987, pp. 1642-1659.

[6] Austin, M. A, Pister, K. S., and Mahin, S. A., "Probabilistic Design of MomentResistant Frames Under Seismic Loading," Journal of Structural Engineering, ASCE, Vol. 113, No. 8, August 1987, pp. 1660-1677.

[7] Bendimerad, M. F., Shah H. C., and Hoskins, T., "Extension of Study on Fundamental Period of Reinforced Concrete Moment-Resisting Frame Structures," Technical Report No. 96, The Blume Earthquake Engineering Center, Stanford University, Stanford, June 1991.

[8] Bertero, V. V., Bendimerad, M. F., and Shah H. C., "Fundamental Period of Reinforced Concrete Moment-Resisting Frame Structures," Technical Report No. 87, The Blume Earthquake Engineering Center, Stanford University, Stanford, October 1988.

[9] Bertero, V. V., and Brokken, S. T., "Infills in Seismic Resistant Buildings," ASCE Journal of Structural Engineering, Vol. 109, No. 6, June 1983, pp. 1337-1361.

[10] Clough R.W., and Penzien, J., "Dynamics of Structures," 2nd Ed., McGraw-Hill, Inc., New York, 1993.

[11] Del Valle, E., and Prince, J., "Analytical and Experimental Studies of Vibration in Two Buildings," Proceeding of Third World Conference on Earthquake Engineering, Volume II, pp.II-458 to II-662, New Zealand, 1965. 
[12] Donovan, N. C., "Determination of Ts, the Characteristic Site Period and Ongoing Code Revisions," Proceeding of ASCESEEAOC Seminar, Fall 1975.

[13] Englekirk, R. E., "Some Comments on the Effectiveness of U.S. Seismic Design Codes and Practice," Proceeding of SEAOC 61st Anmual Convention, pp.107-136, Mexico, 1992.

[14] Frangopol, D. M., and Curley, J. P., "Effects of Damage and Redundancy on Structural Reliability," Journal of Structural Engineering, Vol. 113, No. 7, July 1987, pp. 1533-1549.

[15] Freeman, S. A., "Equating Dynamic Analysis to Static Code Provisions," Proceedings of ASCE Structures Congress, May 1989.

[16] Freeman, S. A., Czamecki, R. M., and Honda, K. K., "Significance of Stiffness Assumptions on Lateral Force Criteria," ACI Publication SP-63, American Concrete Institute, Detroit, 1980, pp. 437-451.

[17] Freeman, S. A., "Introduction to New Features of the SEAOC Blue Book," Proceeding of ASCESEAOC Seminar, Fall 1975.

[18] Gates, W. E., and Foth, V.A., "Building Period Correlation," Report to the Applied Technology Council, 1975.

[19] Gere, J. M., and Timoshenko, S. P., "Mechanics of Materials," Third Ed., PWSKENT Publishing Co., Boston, 1990.

[20] Ghosh, S. K., and Domel, A. W., "Design of Concrete Buildings for Earthquake and Wind Forces," Portland Cement Association and International Conference of Building Officiais, 1992.

[21] Ghosh, S. K., "A Comparative Study of Some of the Seismic Provisions of the Proposed SEAOC Recommendations," The Uniform Building Code 1982 Edition, and the ATC 3-06 Resource Document, Portland Cement Association, Sept. 1984.

[22] Gulkan, P., and Sozen, M. A., "Inelastic Responses of Reinforced Concrete Structures to Earthquake Motions," Publication SP-53, American Concrete Institute, Detroit, 1974, pp 109-115.

[23] Gupta A K., "Response Spectrum Method in Seismic Analysis and Design of Structures," Blackwell Scientific Publications, Cambridge, 1990. 
[24] Hadidi-Tamjid, H., "Statistical Response of Inelastic SDOF Systems Subjected to Earthquakes," Ph.D. Dissertation, Stanford University, Stanford, 1987.

[25] Hart, G. C., "Development of Inelastic Reduction Factors to Provide an Elastic Design Procedures," Proceedings of ASCE Structures Congress, May 1989.

[26] International Conference of Building Officials, "Uniform Building Code," 1988 and 1994 Editions.

[27] Kleijnen, J. P. C., "Statistical Techniques in Simulation," Ist Ed., Marcel Dekker, New York, 1975.

[28] Krawinkler, H., and Nassar, A, "Damage Potential of Whittier Narrows Ground Motions," The Blume Earthquake Engineering Center, Stanford University, Stanford, 1990.

[29] Lapin, L. L., "Probability and Statistics for Modern Engineering," 2nd Ed., PWSKENT, Boston, 1990.

[30] Lashkari-Irvani, B., "Ductility Studies for Bilinear SDOF Systems Under Severe Earthquake Motion," Master Thesis, Stanford University, Stanford, March 1979.

[31] Marek, P., and Guštar, M., "M-Star"TM Computer Program," Distributor: HAB Int., Davis, California, 1992.

[32] Marek, P., and Guštar, M., "M-Star TM Users' Guide," Praha, Czechoslovakia, 1992.

[33] Marek, P., Guštar, M., and Anagnos, T., "Simulation-Based Reliability Assessment for Structural Engineers," CRC Press, Inc., Florida, 1995.

[34] McCormac, J. C., "Design of Reinforced Concrete," 3rd Ed., Harper Collins College Publishers, New York, 1993.

[35] Mulhern, M. R, and Maley, R. P., "Building Period Measurements Before, During, and After the San Fernando Earthquake," In San Fernando, California, Earthquake of February 9, 1971, NOAA/EERI, Murphy, L. M., Ed., Vol. 1, Part B, 1973.

[36] Newmark, N. M. and Veletsos, A. S., "Effects of Inelastic Behavior on the Response of Simple Systems to Earthquake Motions," Proceedings of Fourth World Conference on Earthquake Engineering, Vol. II, Tokyo, Japan, 1960. 
[37] Newmark, N. M., and Hall, W. J., "Procedure and Criteria for Earthquake Resistant Design," Building Science Series No. 46, National Bureau of Standards, Washington, D.C., Feb. 1973, pp. 209-236.

[38] O'Connor, J. M., and Ellingwood, B., "Reliability of Nonlinear Structures with Seismic Loading," Journal of Structural Engineering, ASCE, Vol.113, No.5, May 1987, pp.1011-1027.

[39] Osteraas, J. D., and Krawinkler H., "Strength and Ductility Considerations in Seismic Design," Technical Report No. 90, The Blume Earthquake Engineering Center, Stanford University, Stanford, August 1990.

[40] Pardeon, G. C., "Imperical County Service Building Ambient Vibration Test Results," Christchurch, New Zealand, University of Canterbury, Report 79-14, 1979.

[41] Poland, C. D., "SEAOC Vision 2000, A Comprehensive Approach Towards the Development of Performance-based Seismic Design Standards," Proceedings of SEAOC 63rd Anmual Convention, Oct. 1994, Lake Tahoe, pp. 265-268.

[42] Porush, A. R and Zacher, E. G., "SEAOC, the Blue Book and Seismic Codes Past, Present, and Future," Proceedings of SEAOC 56th Anmual Convention, Oct. 1987.

[43] Seismology Committee, Structural Engineers Association of California (SEAOC), "Recommended Lateral Force Requirements and Commentary (Blue Book)," 1988 and 1990 Editions.

[44] Stephens, J. E., "A Damage Function Using Structural Response Measurements," Proceedings of ASCE National Convention, May 1985, pp. 22-39.

[45] Sues, R. H., Wen, Y., and Ang, A. H.-S., "Stochastic Evaluation of Seismic Structural Performance," Journal of Structural Engineering, Vol. 111, No. 6, June 1985, pp. 1204-1218.

[46] Velkov, M., "Ductility Factor (Discussions on Definitions)," Proceedings of Fourth European Symposium on Earthquake Engineering, London, September 1972.

[47] Vukazich, S. M., "Nonlinear Dynamic Response of Frames Using Lanczos Modal Analysis," Ph.D. Dissertation, University of California at Davis, Davis, Dec. 1993.

[48] Yang, C. Y., Random Vibration of Structures, Wiley-Interscience, New York, 1986. 


\section{APPENDIX A \\ Summary of M-Star TM Computer Program}

M-Star is a simulation-based computer program used for the probabilistic evaluation and solution of formulas with up to 30 random variables ([31] and [32]). Each variable is expressed by its bounded histogram. The investigated formula may also contain constant arguments (i.e., $\pi$ ), numbers (i.e., $1,-23.2$ ), operators (i.e.,,,$+- \eta$, and functions (i.e., sin, log). A complete list of valid symbols and constants can be found in References [31] and [32]. For application of M-Star see Reference [33].

In M-Star, to represent the distributions of random numbers for sampling, using the simulation techniques, bounded frequency histograms are used. The random numbers can be generated using different random number generators. The number of random sampling cycles for a particular problem are based on the character of the problem. Marek et al. ([31], [32] and [33]) recommend that for simple problems using 20,000 to 40,000 steps should provide reasonable results.

While explaining M-Star in detail is beyond the scope of this study, it is important to briefly describe how this program works to fully interpret the results. First, the targeted formula, its arguments (variables and maybe constants), and the number of sampling cycles (steps) must be defined in the form of a configuration file. M-Star samples the variable 
arguments of the formula from the histograms of the variables. At the end of each cycle the assigned values for each variable are used to calculate the value of the investigated formula. After the desired numbers of cycles, a histogram is created showing the bounds and frequency of occurrence of calculated values. A complete list of valid symbols and the instructions on how to run the program can be found in Reference [33].

The results obtained from $M$-Star can represent ([31] and [32]):

- Numerical characteristics of the probability density function of the investigated formula,

- The shape of the resulting histogram representing the probability density function of the investigated formula,

- Quantiles corresponding to assigned probabilities,

- Values of probabilities corresponding to the assigned quantiles,

- The sensitivity of a formula with respect to the changes in its parameter.

The "general version" of M-Star was first developed in 1992 by Pavel Marek and Milan Guštar. Since its development, it has been applied to solve many civil engineering problems by Marek et al. Reference [33] is a collection of some of these problems. 